\title{
Enhanced recovery protocols for major upper gastrointestinal, liver and pancreatic surgery (Review)
}

\author{
Bond-Smith G, Belgaumkar AP, Davidson BR, Gurusamy KS
}

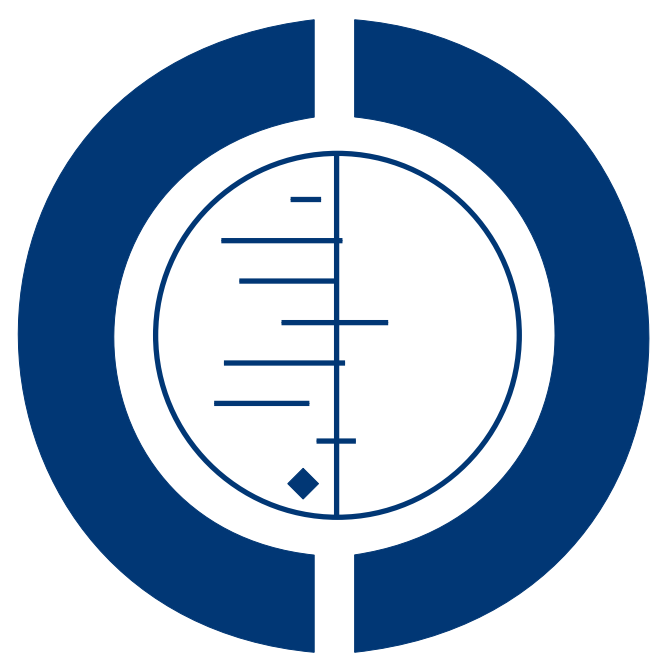

\section{THE COCHRANE COLLABORATION $^{\circledR}$}

This is a reprint of a Cochrane review, prepared and maintained by The Cochrane Collaboration and published in The Cochrane Library 2016, Issue 2

http://www.thecochranelibrary.com

\section{WILEY}


TABLE OF CONTENTS

HEADER

ABSTRACT

PLAIN LANGUAGE SUMMARY

OBJECTIVES

METHODS

Figure 1.

RESULTS

Figure 2.

Figure 3.

DISCUSSION

AUTHORS' CONCLUSIONS

ACKNOWLEDGEMENTS

REFERENCES

CHARACTERISTICS OF STUDIES

DATA AND ANALYSES .

Analysis 1.1. Comparison 1 Enhanced recovery protocol versus standard care, Outcome 1 Short-term mortality. .

Analysis 1.2. Comparison 1 Enhanced recovery protocol versus standard care, Outcome 2 Serious adverse events (proportion).

Analysis 1.3. Comparison 1 Enhanced recovery protocol versus standard care, Outcome 3 Serious adverse events (number).

Analysis 1.4. Comparison 1 Enhanced recovery protocol versus standard care, Outcome 4 Health-related quality of life.

Analysis 1.5. Comparison 1 Enhanced recovery protocol versus standard care, Outcome 5 Mild adverse events (proportion).

Analysis 1.6. Comparison 1 Enhanced recovery protocol versus standard care, Outcome 6 Mild adverse events (number).

Analysis 1.7. Comparison 1 Enhanced recovery protocol versus standard care, Outcome 7 Length of hospital stay.

Analysis 1.8. Comparison 1 Enhanced recovery protocol versus standard care, Outcome 8 Readmissions.

Analysis 1.9. Comparison 1 Enhanced recovery protocol versus standard care, Outcome 9 Costs.

Analysis 2.1. Comparison 2 Enhanced recovery protocol versus standard care (subgroup analysis), Outcome 1 Short-term mortality.

Analysis 2.2. Comparison 2 Enhanced recovery protocol versus standard care (subgroup analysis), Outcome 2 Serious adverse events (proportion).

Analysis 2.3. Comparison 2 Enhanced recovery protocol versus standard care (subgroup analysis), Outcome 3 Serious adverse events (number).

Analysis 2.4. Comparison 2 Enhanced recovery protocol versus standard care (subgroup analysis), Outcome 4 Healthrelated quality of life.

Analysis 3.1. Comparison 3 Enhanced recovery protocol versus standard care (sensitivity analysis), Outcome 1 Healthrelated quality of life.

Analysis 3.2. Comparison 3 Enhanced recovery protocol versus standard care (sensitivity analysis), Outcome 2 Length of hospital stay.

Analysis 3.3. Comparison 3 Enhanced recovery protocol versus standard care (sensitivity analysis), Outcome 3 Costs.

ADDITIONAL TABLES

APPENDICES

WHAT'S NEW

CONTRIBUTIONS OF AUTHORS

DECLARATIONS OF INTEREST

SOURCES OF SUPPORT

DIFFERENCES BETWEEN PROTOCOL AND REVIEW

Enhanced recovery protocols for major upper gastrointestinal, liver and pancreatic surgery (Review)

Copyright (c) 2016 The Cochrane Collaboration. Published by John Wiley \& Sons, Ltd. 


\title{
[Intervention Review] \\ Enhanced recovery protocols for major upper gastrointestinal, liver and pancreatic surgery
}

\author{
Giles Bond-Smith ${ }^{1}$, Ajay P Belgaumkar ${ }^{2}$, Brian R Davidson ${ }^{3}$, Kurinchi Selvan Gurusamy ${ }^{3}$ \\ ${ }^{1}$ Department of Hepatobiliary Surgery, Churchill Hospital, Oxford, UK. ${ }^{2}$ HPB and Liver Transplant Surgery, 8 South, Royal Free \\ London NHS Foundation Trust, London, UK. ${ }^{3}$ Department of Surgery, Royal Free Campus, UCL Medical School, London, UK \\ Contact address: Kurinchi Selvan Gurusamy, Department of Surgery, Royal Free Campus, UCL Medical School, Pond Street, London, \\ NW3 2QG, UK. k.gurusamy@ucl.ac.uk.
}

Editorial group: Cochrane Upper GI and Pancreatic Diseases Group.

Publication status and date: Edited (no change to conclusions), published in Issue 2, 2016.

Review content assessed as up-to-date: 26 March 2015.

Citation: Bond-Smith G, Belgaumkar AP, Davidson BR, Gurusamy KS. Enhanced recovery protocols for major upper gastrointestinal, liver and pancreatic surgery. Cochrane Database of Systematic Reviews 2016, Issue 2. Art. No.: CD011382. DOI: 10.1002/14651858.CD011382.pub2.

Copyright (C) 2016 The Cochrane Collaboration. Published by John Wiley \& Sons, Ltd.

\begin{abstract}
A B S T R A C T
Background

'Fast-track surgery' or 'enhanced recovery protocol' or 'fast-track rehabilitation', incorporating one or more elements of preoperative education, pain relief, early mobilisation, enteral nutrition and growth factors, may improve health-related quality of life and reduce length of hospital stay and costs. The role of enhanced recovery protocols in major upper gastrointestinal, liver and pancreatic surgery is unclear.
\end{abstract}

\section{Objectives}

To assess the benefits and harms of enhanced recovery protocols compared with standard care (or usual practice) in major upper gastrointestinal, liver and pancreatic surgery.

\section{Search methods}

We searched the Cochrane Central Register of Controlled Trials (CENTRAL; Cochrane Library; 2015, Issue 3), MEDLINE, EMBASE and Science Citation Index Expanded until March 2015 to identify randomised trials. We also searched the references of included trials to identify further trials.

\section{Selection criteria}

We considered only randomised controlled trials (RCTs) performed in people undergoing major upper gastrointestinal, liver and pancreatic surgery, irrespective of language, blinding or publication status for inclusion in the review.

\section{Data collection and analysis}

Two review authors independently identified trials and independently extracted data. We calculated the risk ratio (RR), mean difference (MD), or standardised mean difference (SMD) with 95\% confidence intervals (CIs) using both fixed-effect and random-effects models using Review Manager 5, based on available case analysis.

Enhanced recovery protocols for major upper gastrointestinal, liver and pancreatic surgery (Review)

Copyright @ 2016 The Cochrane Collaboration. Published by John Wiley \& Sons, Ltd. 


\section{Main results}

Ten studies met the inclusion criteria for the review, and nine studies provided information on one or more outcomes for the review. A total of 1014 participants were randomly assigned to the enhanced recovery protocol (499 participants) or standard care (515 participants) in the nine RCTs. Most of the trials included low anaesthetic risk participants with high performance status undergoing different upper gastrointestinal, liver and pancreatic surgeries. Eight trials incorporated more than one element of the enhanced recovery protocol. All of the trials were at high risk of bias. The overall quality of evidence was low or very low.

None of the trials reported long-term mortality, medium-term health-related quality of life(three months to one year), time to return to normal activity, or time to return to work. The difference between the enhanced recovery protocol and standard care were imprecise for short-term mortality (enhanced recovery protocol: 4/425 (adjusted proportion = 0.6\%); standard care: 1/443 (0.2\%); seven trials; 868 participants; RR 2.79; 95\% CI 0.44 to 17.73 ; very low quality evidence), proportion of people with serious adverse events (enhanced recovery protocol: $4 / 157$ (adjusted proportion $=0.6 \%$ ); standard care: 0/184 (0.0\%); two trials; 341 participants; RR 5.57; $95 \%$ CI 0.68 to 45.89; very low quality evidence), number of serious adverse events (enhanced recovery protocol: $34 / 421$ (8 per 100 participants); standard care: $46 / 438$ (11 per 100 participants); seven trials; 859 participants; rate ratio 0.72 ; $95 \%$ CI 0.45 to 1.13 ; very low quality evidence), health-related quality of life (four trials; 373 participants; SMD 0.29; 95\% CI -0.04 to 0.62 ; very low quality evidence) and hospital readmissions (enhanced recovery protocol: 14/355 (adjusted proportion $=3.3 \%$ ); standard care: $9 / 378(2.4 \%$ ); seven trials; 733 participants; RR 1.4; 95\% CI 0.69 to 2.87; very low quality evidence). The enhanced recovery protocol group had a lower proportion of people with mild adverse events (enhanced recovery protocol: $31 / 254$ (adjusted proportion $=10.9 \%$ ); standard care: 51 / 271 (18.8\%); four trials; 525 participants; RR 0.58; 95\% CI 0.39 to 0.85; low quality evidence), fewer number of mild adverse events (enhanced recovery protocol: 69/499 (13 per 100 participants); standard care: 128/515 (25 per 100 participants); nine trials; 1014 participants; rate ratio 0.52 ; $95 \%$ CI 0.39 to 0.70 ; low quality evidence), shorter length of hospital stay (nine trials; 1014 participants; MD -2.19 days; $95 \%$ CI -2.53 to -1.85; low quality evidence) and lower costs (four trials; 282 participants; MD USD -6300; $95 \%$ CI -8400 to -4200 ; low quality evidence) than standard care group.

\section{Authors' conclusions}

Based on low quality evidence, enhanced recovery protocols may reduce length of hospital stay and costs (primarily because of reduction in hospital stay) in people undergoing major upper gastrointestinal, liver and pancreatic surgeries. However, the validity of the results is uncertain because of the risk of bias in the trials and the way the outcomes were measured. Future RCTs should be conducted with low risk of bias, and measure clinically important outcomes for including the three months to one year period.

\section{PLAIN LANGUAGE SUMMARY}

\section{Enhanced recovery protocols in people undergoing major surgeries of food pipe (oesophagus), stomach, liver and pancreas Review question}

Are enhanced recovery protocols beneficial or harmful when compared to standard surgery in people undergoing major surgeries of food pipe (oesophagus), stomach, liver and pancreas?

\section{Background}

'Fast-track surgery' or 'enhanced recovery protocol' or 'fast-track rehabilitation' incorporates one or more of the following components: patient education before surgery, pain relief during and after surgery, early mobilisation after surgery, nutritional supplements, and feeding through the mouth or through a tube introduced into the gut through the nose or through the tummy wall rather than by drip to quicken the recovery after surgery. The benefits and harms of using an enhanced recovery protocol in people undergoing major surgeries of oesophagus, stomach, liver and pancreas are not known. We sought to resolve this issue by searching for existing studies on the topic. We included all studies whose results were reported until 26 March 2015.

\section{Study characteristics}

Ten studies met the inclusion criteria for the review, and nine studies provided information for the review. A total of 1014 participants received an enhanced recovery protocol (499 participants) or standard care (515 participants) in the nine trials. The decision on whether a participant received an enhanced recovery protocol or standard care was made using methods similar to the toss of a coin, ensuring that the participants in the two groups were similar. One additional trial (including 33 participants) also performed the same comparison

Enhanced recovery protocols for major upper gastrointestinal, liver and pancreatic surgery (Review) 
but did not provide any information for this review. Most of the trials included persons who were healthy in aspects other than the condition requiring surgery. Eight trials incorporated more than one component of the enhanced recovery protocol.

\section{Key results}

None of the trials reported long-term deaths, medium-term health-related quality of life (three months to one year), time to return to normal activity, or time to return to work. The difference between enhanced recovery protocols and standard care was imprecise for short-term deaths, percentage of people with major complications, total number of major complications, health-related quality of life and hospital readmissions. Enhanced recovery protocols had a lower percentage of people with minor complications, fewer minor complications, shorter length of hospital stay (approximately two days shorter hospital stay per person) and lower costs (cost savings of approximately USD 6300 per person) compared to standard care. Because the trials were of poor quality and did not include clinically important end points, future high quality studies are needed in this field.

\section{Quality of the evidence}

The quality of evidence was low or very low. As a result, there is a lot of uncertainty regarding the results. 


\section{SUMMARY OF FINDINGSFOR THE MAINCOMPARISON [Explanation]}

Enhanced recovery protocols versus standard care for major upper gastrointestinal, liver and pancreatic surgery

Patient or population: people with major upper gastrointestinal, liver and pancreatic surgery

Settings: secondary or tertiary care

Intervention: enhanced recovery protocol

Control: standard care

\begin{tabular}{|c|c|c|c|c|c|c|}
\hline \multirow[t]{3}{*}{ Outcomes } & \multicolumn{2}{|c|}{ Illustrative comparative risks* $(95 \% \mathrm{CI})$} & \multirow{3}{*}{$\begin{array}{l}\text { Relative effect } \\
(95 \% \mathrm{CI})\end{array}$} & \multirow{3}{*}{$\begin{array}{l}\text { No of Participants } \\
\text { (studies) }\end{array}$} & \multirow{3}{*}{$\begin{array}{l}\text { Quality of the evidence } \\
\text { (GRADE) }\end{array}$} & \multirow[t]{3}{*}{ Comments } \\
\hline & Assumed risk & Corresponding risk & & & & \\
\hline & Control & $\begin{array}{l}\text { Enhanced recovery pro- } \\
\text { tocol versus standard } \\
\text { care }\end{array}$ & & & & \\
\hline
\end{tabular}

None of the trials reported long-term mortality, medium-term health-related quality of life (3 months to 1 year), time to return to normal activity, or time to return to work.

\begin{tabular}{|c|c|c|c|c|c|c|}
\hline Short-term mortality & 2 per 1000 & $\begin{array}{l}6 \text { per } 1000 \\
(1 \text { to } 40)\end{array}$ & $\begin{array}{l}\text { RR } 2.79 \\
(0.44 \text { to } 17.73)\end{array}$ & $\begin{array}{l}868 \\
\text { (7 studies) }\end{array}$ & $\begin{array}{l}\oplus \bigcirc \bigcirc \bigcirc \\
\text { very low } \mathbf{l}^{1,2,3}\end{array}$ & \\
\hline $\begin{array}{l}\text { Serious adverse events } \\
\text { (proportion) }\end{array}$ & 1 per 1000 & $\begin{array}{l}\mathbf{6} \text { per } \mathbf{1 0 0 0} \\
(1 \text { to } 46)\end{array}$ & $\begin{array}{l}\text { RR } \mathbf{5 . 5 7} \\
\text { (0.68 to 45.89) }\end{array}$ & $\begin{array}{l}341 \\
\text { (2 studies) }\end{array}$ & $\begin{array}{l}\oplus \bigcirc \bigcirc \bigcirc \\
\text { very low } \text { low }^{1,2,3}\end{array}$ & $\begin{array}{l}\text { Since there were no se- } \\
\text { rious adverse events in } \\
\text { the control group (in the } \\
\text { two trials that reported } \\
\text { the proportion of partic- } \\
\text { ipants with serious ad- } \\
\text { verse events), the con- } \\
\text { trol group risk was stated } \\
\text { as } 0.1 \% \text { for this outcome } \\
\text { alone }\end{array}$ \\
\hline $\begin{array}{l}\text { Serious adverse events } \\
\text { (number) }\end{array}$ & 105 per 1000 & $\begin{array}{l}76 \text { per } 1000 \\
(47 \text { to } 119)\end{array}$ & $\begin{array}{l}\text { Rate ratio } 0.72 \\
(0.45 \text { to } 1.13)\end{array}$ & $\begin{array}{l}859 \\
\text { (7 studies) }\end{array}$ & $\begin{array}{l}\oplus \bigcirc \bigcirc \bigcirc \\
\text { very low } \mathbf{l}^{1,2,3}\end{array}$ & \\
\hline
\end{tabular}




\begin{tabular}{|c|c|c|c|c|c|c|}
\hline $\begin{array}{l}\text { Mild adverse events } \\
\text { (number) }\end{array}$ & 249 per 1000 & $\begin{array}{l}129 \text { per } 1000 \\
(97 \text { to } 174)\end{array}$ & $\begin{array}{l}\text { Rate ratio } \mathbf{0 . 5 2} \\
(0.39 \text { to } 0.70)\end{array}$ & $\begin{array}{l}1014 \\
\text { (9 studies) }\end{array}$ & $\begin{array}{l}\oplus \oplus \bigcirc \bigcirc \\
\text { low }^{1}\end{array}$ & \\
\hline Length of hospital stay & $\begin{array}{l}\text { The mean length of hos- } \\
\text { pital stay in the control } \\
\text { groups was } \\
\mathbf{8} \text { days }\end{array}$ & $\begin{array}{l}\text { The mean length of hos- } \\
\text { pital stay in the interven- } \\
\text { tion groups was } \\
\mathbf{2 . 1 9} \text { lower } \\
\text { ( } 2.53 \text { to } 1.85 \text { lower) }\end{array}$ & & $\begin{array}{l}1014 \\
\text { (9 studies) }\end{array}$ & $\begin{array}{l}\oplus \oplus \bigcirc \bigcirc \\
\text { low }^{1}\end{array}$ & $\begin{array}{l}\text { The length of hospital stay } \\
\text { reported in the trials in- } \\
\text { cluded only the length } \\
\text { of hospital stay during } \\
\text { the admission for surgery } \\
\text { and does not include the } \\
\text { readmissions }\end{array}$ \\
\hline Readmissions & 24 per 1000 & $\begin{array}{l}\mathbf{3 3} \text { per } \mathbf{1 0 0 0} \\
(16 \text { to } 68)\end{array}$ & $\begin{array}{l}\text { RR } 1.4 \\
(0.69 \text { to } 2.87)\end{array}$ & $\begin{array}{l}733 \\
\text { (7 studies) }\end{array}$ & $\begin{array}{l}\oplus \bigcirc \bigcirc \bigcirc \\
\text { very low } \mathbf{l}^{1,2,3}\end{array}$ & \\
\hline Costs & $\begin{array}{l}\text { The mean costs in the } \\
\text { control groups were } \\
\text { USD } 7000\end{array}$ & $\begin{array}{l}\text { The mean costs in the in- } \\
\text { tervention groups were } \\
\mathbf{0 . 6 3} \text { lower } \\
\text { ( } 0.84 \text { to } 0.42 \text { lower) }\end{array}$ & & $\begin{array}{l}282 \\
\text { (4 studies) }\end{array}$ & $\begin{array}{l}\oplus \oplus \bigcirc \bigcirc \\
\text { low }^{1}\end{array}$ & \\
\hline
\end{tabular}

*The basis for the assumed risk is the mean control group risk. The corresponding risk (and its $95 \%$ confidence interval) is based on the assumed risk in the comparison group and the relative effect of the intervention (and its $95 \% \mathrm{Cl}$ ).

Cl: Confidence interval; RR: Risk ratio; 
GRADE Working Group grades of evidence

High quality: Further research is very unlikely to change our confidence in the estimate of effect.

Moderate quality: Further research is likely to have an important impact on our confidence in the estimate of effect and may change the estimate.

Low quality: Further research is very likely to have an important impact on our confidence in the estimate of effect and is likely to change the estimate.

Very low quality: We are very uncertain about the estimate.

The risk of bias was high in all the trials.

${ }^{2}$ The confidence intervals were wide (overlaps 0 and 0.75 or 1.25 ).

3 The total sample size was less than the sample required in a single trial.

${ }^{4}$ The confidence intervals were wide (overlaps 0 and 0.25 or -0.25 ) 


\section{B A C K G R O U N D}

\section{Description of the condition}

Upper gastrointestinal disorders include diseases affecting the oesophagus, stomach, liver, gallbladder and pancreas. The definition of major upper gastrointestinal, liver and pancreatic surgery is variable. One definition that we have used in this review includes all upper gastrointestinal, liver and pancreatic surgeries that have been excluded from the British Association of Day Surgery Directory of Procedures (BADS 2012), as well as surgeries such as transhiatal oesophagectomy, gastrectomy (irrespective of whether a total or subtotal distal gastrectomy is performed), liver resection (irrespective of the number of segments resected and the aetiology), pancreatic resection (irrespective of whether a pancreaticoduodenectomy or a distal pancreatectomy is performed, and irrespective of whether the pylorus is preserved), pancreatic drainage procedures (for chronic pancreatitis) and open pancreaticojejunostomy or pancreaticogastrostomy for pseudocyst. In upper gastrointestinal surgeries that are included in the British Association of Day Surgery Directory of Procedures (BADS 2012), early mobilisation and discharge are recommended when possible, and patients are admitted because of coexisting medical illnesses, for administrative reasons, because of complications related to surgery, or because of intolerance to surgery. As will be evident from the description of the intervention, early mobilisation is one of the elements of an enhanced recovery protocol; therefore this review includes only upper gastrointestinal, liver and pancreatic surgeries that are not included in the British Association of Day Surgery Directory of Procedures (BADS 2012). The number of major upper gastrointestinal, liver and pancreatic surgeries performed each year is difficult to estimate. In the UK alone, approximately 25,000 major upper gastrointestinal, liver and pancreatic surgeries are performed, costing approximately GBP 150 million each year (Hospital Episode Statistics 2013).

\section{Description of the intervention}

'Fast-track surgery' or 'enhanced recovery protocol' or 'fast-track rehabilitation' after surgery, again can be variably defined, and involves one or more of the following elements (Kehlet 1997).

1. Preoperative information and teaching.

2. Decreased stress related to surgery.

3. Pain relief.

4. Exercise (early mobilisation).

5. Enteral nutrition.

6. Growth factors.

\section{How the intervention might work}

Enhanced recovery protocols aim to decrease pathophysiological changes after surgery, including surgical stress, pain, immunosuppression, nausea, vomiting and ileus, hypoxaemia, immobilisation leading to blood clots in the legs and malnutrition leading to catabolism and muscle wasting (Kehlet 1997).

\section{Why it is important to do this review}

Implementation of enhanced recovery protocols involves considerable planning (including identifying the elements that need to be incorporated into the protocol for a particular surgery) and deployment (which involves educating and training the staff and encouraging staff members, including surgeons, to follow a unified protocol). Deployment may involve changing traditions and beliefs of surgeons and other clinicians who may be reluctant to change their traditional practices, or who may be concerned that the enhanced recovery protocol may be associated with patient risks and harms. It also incurs costs. Thus, implementation of enhanced recovery protocols involves considerable human and resource management. It is therefore essential to assess whether an enhanced recovery protocol is effective for major upper gastrointestinal, liver and pancreatic surgery. No Cochrane review on this topic has been conducted.

\section{O B J E C T I VES}

To assess the benefits and harms of enhanced recovery protocols compared with standard care (or usual practice) in major upper gastrointestinal, liver and pancreatic surgery.

\section{METHODS}

\section{Criteria for considering studies for this review}

\section{Types of studies}

We included randomised controlled trials (RCTs) reported as fulltext, those published as abstract only, and those with unpublished data.

\section{Types of participants}

We included adults, or children, or both, undergoing major upper gastrointestinal, liver and pancreatic surgery such as transhiatal oesophagectomy, gastrectomy (irrespective of whether a total or subtotal distal gastrectomy is performed), liver resection (irrespective of the number of segments resected and the aetiology), pancreatic resection (irrespective of whether a pancreaticoduodenectomy or a distal pancreatectomy is performed, and irrespective 
of whether the pylorus is preserved), pancreatic drainage procedures (for chronic pancreatitis) and open pancreaticojejunostomy or pancreaticogastrostomy for pseudocyst.

We excluded upper gastrointestinal, liver and pancreatic surgeries that are included in the British Association of Day Surgery Directory of Procedures (BADS 2012), including laparoscopic cholecystectomy or laparoscopic fundoplication, as patients are discharged on the same day when they have mobilised adequately.

\section{Types of interventions}

We included trials comparing an enhanced recovery protocol with usual care, provided that the only difference between randomly assigned groups is the use of an enhanced recovery protocol. We will accept the definition proposed by Kehlet 1997, which requires inclusion of one or more of the following elements.

1. Preoperative information and teaching.

2. Decreased stress related to surgery.

3. Pain relief.

4. Exercise (early mobilisation).

5. Enteral nutrition.

6. Growth factors.

We excluded trials comparing different enhanced recovery protocols. We also excluded trials comparing laparoscopic and open surgeries, as the issues surrounding laparoscopic or open surgery are different for different procedures.

\section{Types of outcome measures}

\section{Primary outcomes}

1. Mortality.

i) Short-term mortality (in-hospital mortality or mortality within three months).

ii) Long-term mortality (for patients undergoing surgery for cancer).

2. Serious adverse events (within three months). We accepted the following definitions of serious adverse events.

i) Clavien-Dindo classification (Clavien 2009; Dindo 2004): grade III or higher.

ii) International Conference on Harmonisation-Good Clinical Practice (ICH-GCP) guideline (ICH-GCP 1996): serious adverse events defined as any untoward medical occurrences that result in death, are life threatening, require inpatient hospitalisation or prolongation of existing hospitalisation and result in persistent or significant disability/ incapacity.

iii) Individual complications that could clearly be classified as grade III or higher by the Clavien-Dindo classification (Clavien 2009; Dindo 2004), or as a serious adverse event by the ICH-GCP classification.

3. Health-related quality of life (using any validated scale). i) Short-term (until three months).

ii) Medium-term (three months to one year).

\section{Secondary outcomes}

1. Adverse events (within three months). We included all adverse events reported by the study authors, irrespective of their severity.

2. Length of hospital stay (including the index admission for major upper gastrointestinal, liver or pancreatic surgery and any surgical complication-related readmissions).

3. Number of hospital readmissions.

4. Time to return to normal activity (return to preoperative mobility without additional carer support).

5. Time to return to work (for those who were employed previously).

6. Costs (however reported by study authors; we converted costs to the single currency of USD based on the existing conversion rate on the day of the analysis).

The selection of the above clinical outcomes was based on the necessity to assess whether an enhanced recovery protocol decreases complications after surgery and results in earlier postoperative recovery, allowing earlier discharge from hospital, return to normal activity, return to work and improvement in health-related quality of life.

Reporting of the outcomes listed here will not be an inclusion criterion for the review.

\section{Search methods for identification of studies}

\section{Electronic searches}

We conducted a literature search to identify all published and unpublished RCTs until 26th March 2015. This literature search identified potential studies published in all languages. We translated the non-English language papers and fully assessed them for potential inclusion in the review as necessary.

We searched the following electronic databases to identify potential studies.

1. Cochrane Central Register of Controlled Trials

(CENTRAL; Cochrane Library; 2015, Issue 3) (Appendix 1).

2. MEDLINE (OvidSP) (1966 to March 2015) (Appendix 2).

3. EMBASE (OvidSP) (1988 to March 2015) (Appendix 3).

4. Science Citation Index (Web of Knowledge) (1982 to March 2015) (Appendix 4).

We also conducted a search of ClinicalTrials.gov (Appendix 5) and the World Health Organization International Clinical Trials Registry Platform (WHO ICTRP) (Appendix 6) on 26th March 2015. 


\section{Searching other resources}

We checked reference lists of all primary studies and review articles for additional references. We contacted authors of identified trials and asked them to identify other published and unpublished studies.

We searched for errata or retractions from eligible trials on http:/ /www.ncbi.nlm.nih.gov/pubmed on 26th March 2015, but did not find any errata.

\section{Data collection and analysis}

\section{Selection of studies}

Two review authors (GBS and $A B$ ) independently screened titles and abstracts for inclusion of all potential studies identified as a result of the search and coded them as 'retrieve' (eligible or potentially eligible/unclear) or 'do not retrieve.'

We retrieved full-text study reports, and the two review authors (GBS and $A B$ ) independently screened them, identified studies for inclusion and identified and record reasons for exclusion of ineligible studies.

We resolved disagreements through discussion and, when required, consulted a third person (KG). We identified and excluded duplicates and collated multiple reports of the same study, so that each study rather than each report is the unit of interest in the review. We recorded the selection process in sufficient detail to complete a PRISMA (Preferred Reporting Items for Systematic Reviews and Meta-Analyses) flow diagram (Moher 2009; Figure 1), and a Characteristics of excluded studies table. 
Figure I. Study flow diagram.

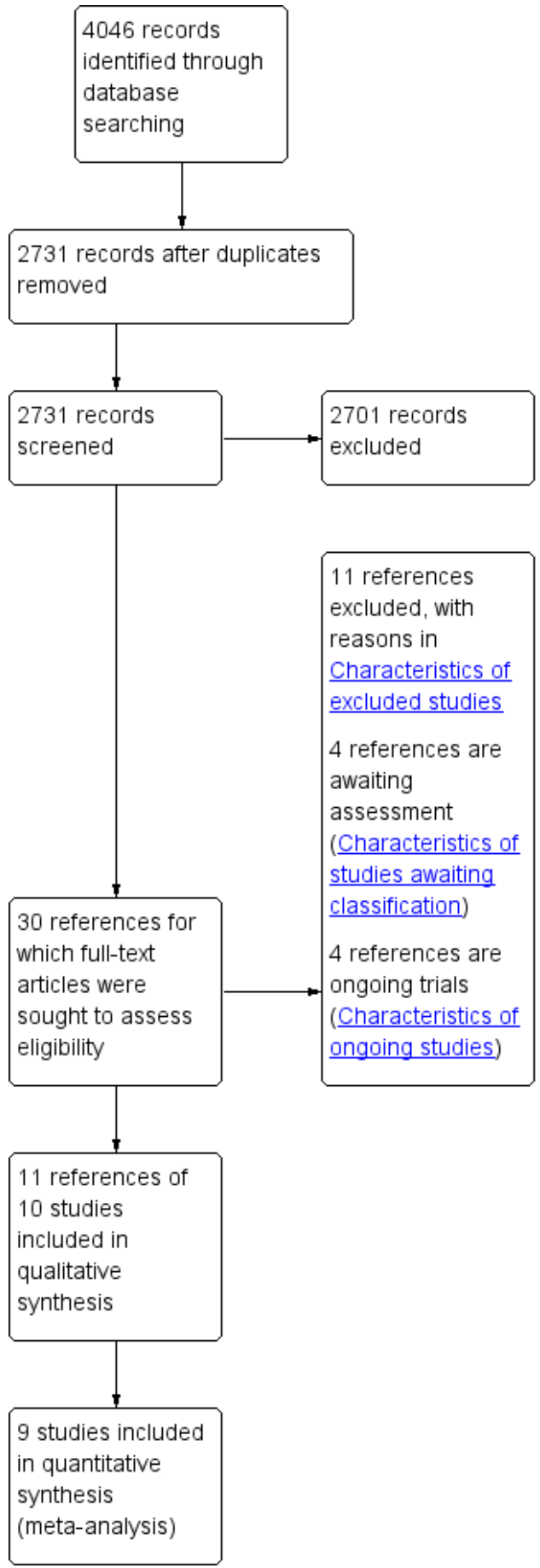




\section{Data extraction and management}

We used a standard data collection form for study characteristics and outcome data that was piloted on two studies in the review. The two review authors (GBS and $\mathrm{AB}$ ) extracted the following study characteristics from included studies.

1. Methods: study design, total duration of study and run-in, number of study centres and locations, study settings, withdrawals, dates of study.

2. Participants: number $(\mathrm{N})$, mean age, age range, gender, inclusion criteria, exclusion criteria.

3. Interventions: interventions, comparisons, concomitant interventions.

4. Outcomes: primary and secondary outcomes specified and collected, time points reported.

5. Notes: funding for trial, notable conflicts of interest of trial authors.

Two review authors (GBS and AB) independently extracted outcome data from the included studies. If outcomes were reported multiple times for the same time point, for example, if shortterm health-related quality of life was reported at six weeks and at three months, we planned to choose the later time point (i.e. three months) for data extraction. For time-to-event outcomes, we planned to extract data to calculate the natural logarithm of the hazard ratio and its standard error using the methods suggested by Parmar 1998.

We planned to include all randomly assigned participants for the medium- and long-term outcomes (e.g. mortality, quality of life), and this was not conditional upon short-term outcomes (e.g. being alive at three months, having a low or high quality of life index at three months).

We noted in the Characteristics of included studies table whether outcome data were reported in an unusable way. We resolved disagreements by reaching consensus or by involving a third person (KG). One review author (KG) copied data from the data collection form into the Review Manager file (RevMan 2014). We double-checked that data were entered correctly by comparing data in the study reports with data presented in the systematic review.

\section{Assessment of risk of bias in included studies}

Two review authors (GBS and $\mathrm{AB}$ ) independently assessed risk of bias for each study, using the criteria outlined in the Cochrane Handbook for Systematic Reviews of Interventions (Higgins 2011). Disagreements were resolved by discussion or through involvement of a third assessor (KG). We assessed risk of bias according to the following domains.

1. Random sequence generation.

2. Allocation concealment.
3. Blinding of participants and personnel.

4. Blinding of outcome assessment.

5. Incomplete outcome data.

6. Selective outcome reporting.

7. Other bias.

We graded each potential source of bias as high, low or unclear risk and provided a quote from the study report together with a justification for our judgement in the 'Risk of bias' table. We summarised risk of bias judgements across different studies for each of the domains listed. We considered blinding separately for different key outcomes when necessary (e.g. for unblinded outcome assessment, risk of bias for all-cause mortality may be very different than for a patient-reported pain scale). When information on risk of bias was related to unpublished data or correspondence with a trialist, we noted this in the 'Risk of bias' table.

When considering treatment effects, we took into account the risk of bias for studies that contribute to those outcomes.

\section{Assesment of bias in conducting the systematic review}

We conducted the review according to the published protocol and reported deviations from the protocol in the Differences between protocol and review' section of this review.

\section{Measures of treatment effect}

We analysed dichotomous data as risk ratios (RRs) and continuous data as mean differences (MDs) when the outcome was reported or converted to the same units in all trials (e.g. hospital stay) or as standardised mean differences (SMDs) when different scales were used in measuring the outcome (e.g. quality of life). We ensured that higher scores for continuous outcomes had the same meaning for the particular outcome, explained the direction to the reader and reported when the directions were reversed.

We calculated rate ratios for outcomes such as adverse events and serious adverse events when it was possible for the same person to experience more than one adverse event (or serious adverse event). If the study authors had calculated the rate ratio of adverse events (or serious adverse events) for intervention versus control on the basis of Poisson regression, we planned to obtain the rate ratio by using the Poisson regression method in preference to the rate ratio calculated using the number of adverse events (or serious adverse events) reported during a specified period. We planned to calculate the hazard ratio for time-to-event outcomes such as longterm mortality and long-term recurrence.

We undertook meta-analyses since all the surgeries were major hepato pancreato biliary surgeries. Trialists commonly indicate when they have skewed data by reporting medians and interquartile ranges. It was not possible to determine whether the data were 
skewed. We attempted to contact the trial authors to provide this information, but we were unable to obtain this information. So, if the median and interquartile range were reported, we imputed the mean and standard deviation (as mentioned in the Dealing with missing data), but we performed a sensitivity analysis, excluding the data from these trials (as mentioned in the Sensitivity analysis). When multiple trial arms were reported in a single trial, we planned to include only the relevant arms. When two comparisons (e.g. enhanced recovery protocol A versus standard care and enhanced recovery protocol $\mathrm{B}$ versus standard care) had to be entered into the same meta-analysis, we planned to pool the results of enhanced recovery protocol A and enhanced recovery protocol B and compare them with standard care. The alternative way of including such trials is to half the control group and compare it with enhanced recovery protocol $\mathrm{A}$ and with enhanced recovery protocol B to avoid double counting. We planned to perform a sensitivity analysis to determine whether results obtained using the two methods of dealing with multi-arm trials led to different conclusions.

\section{Unit of analysis issues}

The unit of analysis was individual study participants undergoing major upper gastrointestinal, liver and pancreatic surgery. If cluster-randomised trials were identified, we planned to obtain the effect estimate adjusted for the clustering effect. If this was not available, we planned to perform a sensitivity analysis by excluding the trial from the meta-analysis, as the variance of the effect estimate unadjusted for cluster effect is less than the actual variance, which is adjusted for cluster effect, inappropriately giving more weight to the cluster-RCT in the meta-analysis.

\section{Dealing with missing data}

We attempted to contact the investigators or study sponsors to verify key study characteristics and to obtain missing numerical outcome data whenever possible (e.g. when a study is identified as an abstract only). We received additional data from two study authors (Jones 2013; Kim 2012). If we were unable to obtain information from investigators or study sponsors, we imputed mean from median (i.e. consider median as the mean) and standard deviation from standard error, interquartile range or P values according to the recommendations of the Cochrane Handbook for Systematic Reviews of Interventions (Higgins 2011), but we assessed the impact of including such studies as indicated in a sensitivity analysis.

If we were unable to calculate the standard deviation from the standard error, interquartile range or P values, we imputed the standard deviation as the highest standard deviation in the remaining trials included in the outcome, while remaining fully aware that this method of imputation will decrease the weight of the studies in the meta-analysis of MDs and will shift the effect towards no effect for SMDs.

\section{Assessment of heterogeneity}

We used the $\mathrm{I}^{2}$ statistic to measure heterogeneity among the trials in each analysis. If we identified substantial heterogeneity as per the Cochrane Handbook for Systematic Reviews of Interventions (greater than $50 \%$ to $60 \%$ ), we planned to explore this by performing prespecified subgroup analysis (Higgins 2011).

\section{Assessment of reporting biases}

We attempted to contact study authors to ask them to provide missing outcome data. When this was not possible, and the missing data were thought to introduce serious bias, we explored the impact of including such studies in the overall assessment of results by a sensitivity analysis.

Since there were fewer than 10 trials for all the outcomes, we did not create and examine a funnel plot to explore possible publication biases. We planned to use Egger's test to determine the statistical significance of the reporting bias (Egger 1997). We planned to use a $\mathrm{P}$ value less than 0.05 to show statistically significant reporting bias.

\section{Data synthesis}

We performed analyses using Review Manager 5.3 (RevMan 2014). We used the Mantel Haenszel method for dichotomous data, inverse variance method for continuous data and generic inverse variance for count data. We planned to use generic inverse variance for time-to-event data. We used both the fixed-effect model (DerSimonian 1986), and random-effects model for the analysis (Demets 1987). In case of discrepancy between the two models, we reported both results; otherwise we reported only the results from the fixed-effect model.

\section{'Summary of findings' table}

We created a 'Summary of findings' table using all outcomes. We used the five GRADE (Grades of Recommendation, Assessment, Development and Evaluation) considerations (study limitations, consistency of effect, imprecision, indirectness and publication bias) to assess the quality of a body of evidence as it related to the studies that contributed data to the meta-analyses for prespecified outcomes.

We used methods and recommendations as described in Section 8.5 and Chapter 12 of the Cochrane Handbook for Systematic Reviews of Interventions (Higgins 2011), and used GRADEpro software (GRADEproGDT 2015). We justified all decisions to downgrade or upgrade the quality of studies by using footnotes and making comments to aid the reader's understanding of the review whenever necessary. We planned to consider whether any additional outcome information could not be incorporated into the meta-analyses and noted this in the comments, stating whether it supported or contradicted the information derived from the metaanalyses. 


\section{Subgroup analysis and investigation of heterogeneity}

We planned to carry out the following subgroup analyses.

1. Different surgeries (e.g. total or subtotal gastrectomy, distal gastrectomy, pancreaticoduodenectomy, distal pancreatectomy).

2. Different enhanced recovery protocols (according to the element that the enhanced recovery protocol is meant to address, for example, pain relief, nutrition).

3. Adults versus children.

We planned to use the primary outcomes in the subgroup analysis. We used the formal $\mathrm{Chi}^{2}$ test for subgroup differences to test for subgroup interactions.

\section{Sensitivity analysis}

We performed sensitivity analysis, as defined a priori, to assess the robustness of our conclusions. This involved:

1. excluding trials at unclear or high risk of bias (one of more of the risk of bias domains is classified as unclear or high);

2. excluding trials for which mean or standard deviation or both were imputed; and

3. excluding cluster-RCTs for which adjusted effect estimates are not reported.

4. different methods of dealing with multi-arm trials (please see Measures of treatment effect).

\section{Reaching conclusions}

We based our conclusions only on findings from the quantitative or narrative synthesis of studies included in this review. We have avoided making recommendations for practice, and our implications for research will give the reader a clear sense of what the focus of future research in the area should be; we have identified remaining uncertainties.

\section{RES U L T S}

\section{Description of studies}

\section{Results of the search}

We identified 4046 references through electronic searches of the Cochrane Central Register of Controlled Trials (CENTRAL) (n = 324), MEDLINE (OvidSP) $(\mathrm{n}=1087)$, EMBASE (OvidSP) $(\mathrm{n}=731)$, Science Citation Index expanded $(\mathrm{n}=1737)$, ClinicalTrials.gov $(n=89)$ and the WHO Trials register $(n=78)$. After removing duplicate references there were 2731 references. We excluded 2701 clearly irrelevant references through reading abstracts. We retrieved a total of 30 references for further assessment in detail, from the full publication. We excluded 11 references for the reasons listed in the Characteristics of excluded studies tables. Four references were references of ongoing trials (Characteristics of ongoing studies). Four references are awaiting classification Of these, two were published as abstracts and it is not clear whether an intervention that can be classified as an enhanced recovery protocol was included as one of the arms (Geubbels 2014; Jin 2013). One reference has been published as full-text but we were unable to obtain the full-text in order to assess eligibility (Wang 2014). One reference was identified as completed in the Clinical Trials.gov trial register, but we could not identify any publication as abstract or full-text. We were unable to obtain the results for any of these trials. Eleven references of 10 RCTs fulfilled the inclusion criteria (Characteristics of included studies). The reference flow is shown in Figure 1.

\section{Included studies}

We included a total of 10 RCTs (Barlow 2011; Jones 2013; Kim 2012; Lemanu 2013; Liu 2010; Lu 2014; Miyachi 2013; Ni 2013; Wang 2010; Zhao 2014). All of the 10 RCTs were two-armed trials. A total of 1115 participants were randomised to either an enhanced recovery protocol or standard recovery protocol group. A total of 68 were excluded after randomisation for various reasons stated in the Characteristics of included studies. The mean or median age in the trials ranged from 44 years to 66 years. The average proportion of females ranged from $17.8 \%$ to $70.5 \%$. The type of surgeries that the participants underwent is summarised in Table 1. Three trials included participants undergoing gastrectomy (Liu 2010; Miyachi 2013; Wang 2010) and three trials included participants undergoing liver surgery (Jones 2013; Lu 2014; Ni 2013). The participants underwent major upper gastrointestinal surgery, laparoscopic distal gastrectomy, laparoscopic sleeve gastrectomy, oesophagectomy in each of the remaining trials (Barlow 2011; Kim 2012; Lemanu 2013; Zhao 2014). The detailed inclusion and exclusion criteria of participants in the different trials are stated in the Characteristics of included studies tables.

The elements of the enhanced recovery protocol that were different between the intervention and control in the different studies are summarised in Table 1 and Characteristics of included studies tables. Seven trials incorporated preoperative patient education in addition to the standard care (Jones 2013; Kim 2012; Lemanu 2013; Liu 2010; Ni 2013; Wang 2010; Zhao 2014). Six trials incorporated a pain relief regimen which was different between the enhanced recovery protocol and standard care (Kim 2012; Lemanu 2013; Liu 2010; Ni 2013; Wang 2010; Zhao 2014). Seven trials incorporated early mobilisation in the enhanced recovery protocol care group in addition to the standard care (Jones 2013; Kim 2012; Lemanu 2013; Liu 2010; Lu 2014; Ni 2013; Wang 2010). Eight trials incorporated early enteral nutrition in one form or the other in addition to the standard care (Barlow 2011; Jones 2013; Kim 2012; Lemanu 2013; Liu 2010; Lu 2014; Ni 2013; Wang 2010). One trial incorporated growth factors in the en- 
hanced recovery protocol care group in addition to the standard care (Miyachi 2013). Eight trials incorporated more than one element of the enhanced recovery protocol in the enhanced recovery protocol group compared to the standard care group (Jones 2013; Kim 2012; Lemanu 2013; Liu 2010; Lu 2014; Ni 2013; Wang 2010; Zhao 2014). The outcomes reported in the trials are summarised in Table 1 . Nine trials including a total of 1014 participants randomised to the enhanced recovery protocol (499 participants) and standard care (515 participants) provided data on one or more outcomes and could be included in the meta-analysis.

\section{Excluded studies}

We excluded three trials as they were comparisons between two enhanced recovery protocols (Gillissen 2011; Hendry 2010; Revie 2012). We excluded four trials as they included patients undergoing surgeries, but were not specific to major upper gastrointestinal, liver or pancreatic surgeries (Cheifetz 2010; Hubner 2012; Serclova 2009; Wattchow 2009). We excluded three studies as they were non-randomised studies (Dejong 2014; Feldman 2014;
Sahoo 2014). We excluded another reference as it was a comment on an included trial (Strobel 2013).

\section{Risk of bias in included studies}

None of the trials were considered to be at low risk of bias. All the trials had unclear or high risk of bias on one or more domains (Figure 2; Figure 3). All-cause mortality is unlikely to be influenced by the lack of blinding, while all the remaining outcomes are likely to be biased towards the enhanced recovery protocol because of lack of blinding. Blinding of participants is impossible for some of the elements of the enhanced recovery protocol (preoperative education and early mobilisation). Eight trials included at least one of preoperative education and early mobilisation (Jones 2013; Kim 2012; Lemanu 2013; Liu 2010; Lu 2014; Ni 2013; Wang 2010; Zhao 2014). It would have been impossible to blind the participants and the healthcare provider in these trials. So, we assessed whether the above trials were at low risk of other biases; none of the trials were at low risk of bias even after excluding the blinding of participants and personnel domain.

Figure 2. Risk of bias graph: review authors' judgements about each risk of bias item presented as percentages across all included studies.

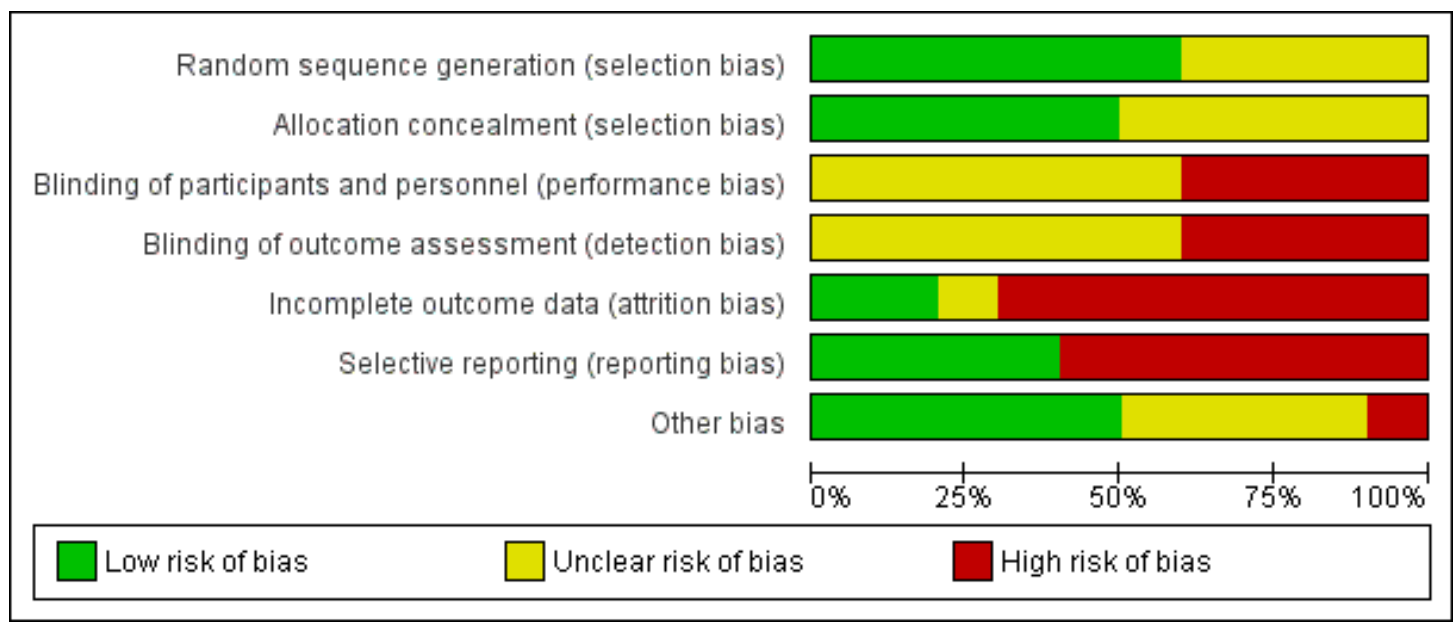

Enhanced recovery protocols for major upper gastrointestinal, liver and pancreatic surgery (Review) 
Figure 3. Risk of bias summary: review authors' judgements about each risk of bias item for each included study.

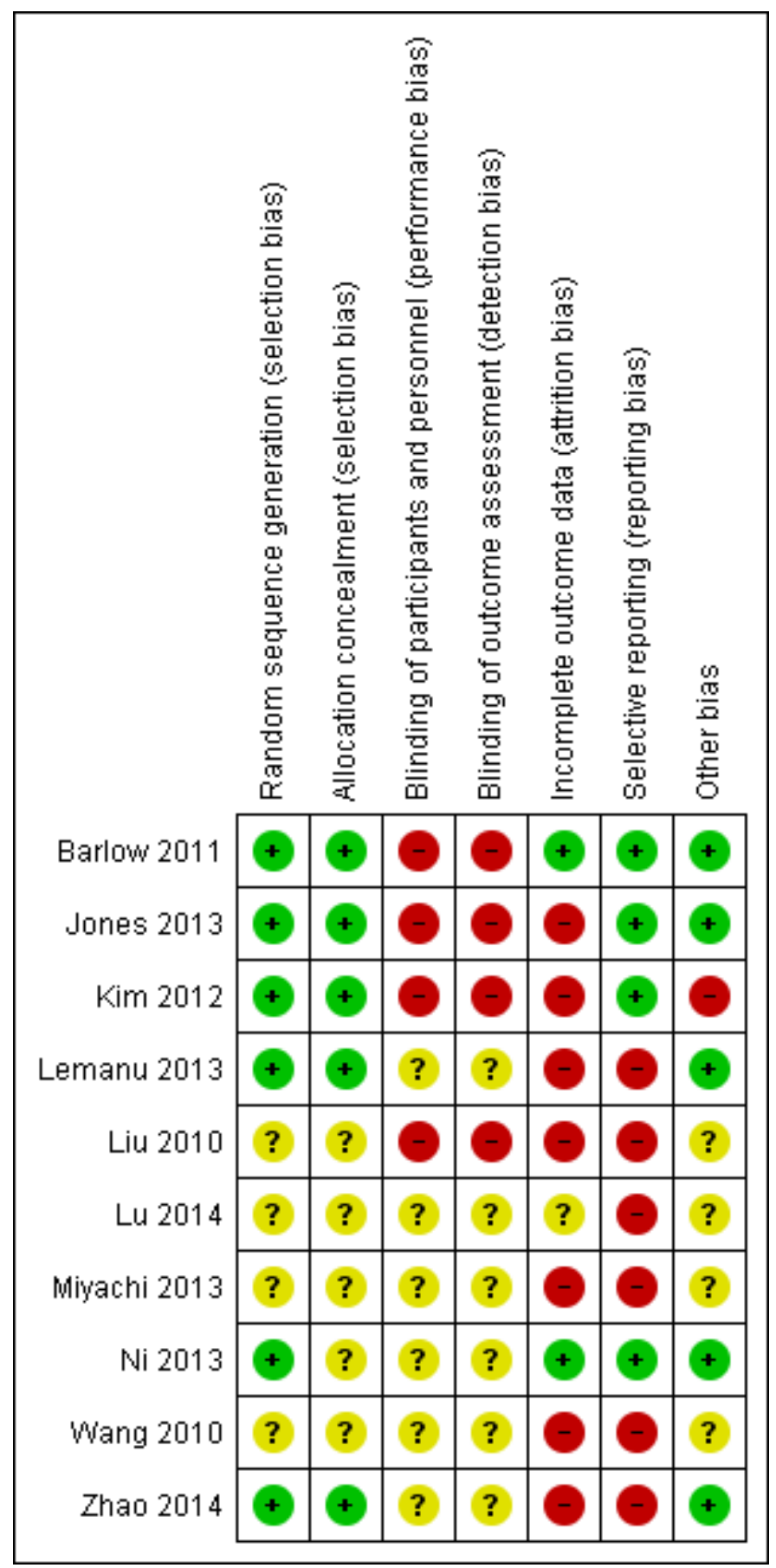




\section{Allocation}

Five trials described random sequence generation and allocation concealment adequately (Barlow 2011; Jones 2013; Kim 2012; Lemanu 2013; Zhao 2014). We considered these five trials to be at low risk of selection bias; the selection bias in the remaining trials was unclear.

\section{Blinding}

No trials reported that the participants and healthcare personnel involved in patient care or the outcome assessors were blinded and so we considered all trials to be at unclear or high risk of performance and detection bias.

\section{Incomplete outcome data}

Two trials had no post-randomisation drop-outs and we considered them to be at low risk of attrition bias (Barlow 2011; Ni 2013). The remaining trials had post-randomisation drop-outs, particularly; they excluded participants who developed complications during surgery, or participants who did not follow the protocol to which they were randomised.

\section{Selective reporting}

Four trials reported mortality and morbidity adequately and we considered them to be at low risk of selective reporting bias ( Barlow 2011; Jones 2013; Kim 2012; Ni 2013). The remaining trials did not report the mortality and morbidity or did not report the severity of the morbidity; we were unable to locate the trial protocol for these trials to compare whether the outcomes reported in the final report were in the same order as in the protocol. We considered these trials to be at high risk of selective reporting.

\section{Other potential sources of bias}

Six trials reported the source of funding (Barlow 2011; Jones 2013; Kim 2012; Lemanu 2013; Ni 2013; Zhao 2014), out of which we considered five trials to be at low risk of bias due to source of funding (Barlow 2011; Jones 2013; Lemanu 2013; Ni 2013; Zhao 2014); the risk of bias due to source of funding was unclear in the remaining trials. We did not identify any other risks of bias in the trials which could have influenced the effect estimates.

\section{Effects of interventions}

See: Summary of findings for the main comparison Enhanced recovery protocol versus standard care for major upper gastrointestinal, liver and pancreatic surgery
None of the trials reported long-term mortality, medium-term health-related quality of life, time to return to normal activity, or time to return to work. A summary of the effect estimates is available in Summary of findings for the main comparison. The quality of evidence was low (mild adverse events: proportion and number of events, length of hospital stay, and costs) or very low (short-term mortality, serious adverse events: proportion and number, health-related quality of life, and readmissions) for the outcomes reported in the trials.

\section{Primary outcomes}

\section{Short-term mortality}

Seven trials (868 participants) reported short-term mortality (Barlow 2011; Jones 2013; Kim 2012; Liu 2010; Lu 2014; Ni 2013; Wang 2010). There was no statistically significant difference in the short-term mortality between the enhanced recovery protocol and standard care (risk ratio (RR) 2.79, 95\% confidence interval (CI) 0.44 to 17.73 ; Analysis 1.1 ). There was no change in the statistical significance by using the random-effects model. There was no evidence of heterogeneity $\left(\mathrm{I}^{2}=0 \%\right.$; $\left.=0.36\right)$.

\section{Serious adverse events}

Two trials (341 participants) reported the proportion of participants with serious adverse events (Kim 2012; Liu 2010). There was no statistically significant difference in the proportion of participants with serious adverse events between the enhanced recovery protocol and standard care (RR 5.57, 95\% CI 0.68 to 45.89 ; Analysis 1.2). There was no change in the statistical significance by using the random-effects model. There was no evidence of heterogeneity $\left(I^{2}=0 \% ; P=0.64\right)$.

Seven trials ( 859 participants) reported the number of serious adverse events (Barlow 2011; Jones 2013; Kim 2012; Lemanu 2013; Lu 2014; Ni 2013; Zhao 2014). There was no statistically significant difference in the number of participants with serious adverse events between the enhanced recovery protocol and standard care (rate ratio $0.72,95 \%$ CI 0.45 to 1.13 ; Analysis 1.3 ). There was no change in the statistical significance by using the random-effects model. There was no evidence of heterogeneity $\left(\mathrm{I}^{2}=16 \% ; \mathrm{P}=\right.$ $0.31)$.

\section{Health-related quality of life (until three months)}

Four trials (373 participants) reported health-related quality of life (Jones 2013; Kim 2012; Lemanu 2013; Ni 2013). One trial measured health-related quality of life at five days after surgery using 
the General Comfort Questionnaire (GCQ measured by Kolcaba Line; Ni 2013). Two trials measured health-related quality of life at 14 days after surgery using the Surgical Recovery Scale (which measures postoperative fatigue) (Lemanu 2013), and the European Organisation for Research and Treatment of Cancer (EORTC) QLQ C-30 (Kim 2012). One trial measured the health-related quality of life at various time points until 28 days after surgery using the EQ-5D questionnaire and reported the area under the curve of the health-related quality of life (Jones 2013). The healthrelated quality of life was statistically significantly better with enhanced recovery protocols than standard care using the fixed-effect model (standardised mean difference (SMD) 0.33, 95\% CI 0.13 to 0.54$)$. However, on using the random-effects model, there was no statistically significant difference in the health-related quality of life between the enhanced recovery protocol and standard care (SMD 0.29, 95\% CI -0.04 to 0.62) (Analysis 1.4). There was moderate heterogeneity $\left(\mathrm{I}^{2}=57 \% ; \mathrm{P}=0.07\right)$. The mean and standard deviation were imputed from the median and $\mathrm{P}$ value from one of the trials (Jones 2013). Exclusion of this trial did not alter the statistical significance of the results (SMD 0.17, 95\% CI -0.19 to 0.53 ; Analysis 3.1).

\section{Secondary outcomes}

\section{Mild adverse events}

Four trials (525 participants) reported the proportion of participants with mild adverse events (Barlow 2011; Kim 2012; Liu 2010; $\mathrm{Lu} 2014$ ). The proportion of participants with mild adverse events was statistically significantly better with enhanced recovery protocols than standard care (RR $0.58,95 \%$ CI 0.39 to 0.85 ) (Analysis 1.5). There was no change in the statistical significance by using the random-effects model. There was no evidence of heterogeneity $\left(\mathrm{I}^{2}=0 \% ; \mathrm{P}=0.87\right)$.

Nine trials (1014 participants) reported the number of mild adverse events (Barlow 2011; Jones 2013; Kim 2012; Lemanu 2013; Liu 2010; Lu 2014; Ni 2013; Wang 2010; Zhao 2014). The number of mild adverse events was statistically significantly better with enhanced recovery protocols than standard care (rate ratio 0.52 , 95\% CI 0.39 to 0.70; Analysis 1.6). There was no change in the statistical significance by using the random-effects model. There was no evidence of heterogeneity $\left(I^{2}=0 \% ; P=0.47\right)$.

\section{Length of hospital stay}

Nine trials (1014 participants) reported length of hospital stay (Barlow 2011; Jones 2013; Kim 2012; Lemanu 2013; Liu 2010; Lu 2014; Ni 2013; Wang 2010; Zhao 2014). The length of hospital stay reported in the trials included only the length of hospital stay during the admission for surgery and does not include the readmissions. The length of hospital stay was statistically significantly shorter with enhanced recovery protocols than standard care (MD -2.19 days, 95\% CI -2.53 to -1.85; Analysis 1.7). There was no change in the statistical significance by using the randomeffects model. There was moderate heterogeneity $\left(\mathrm{I}^{2}=66 \% ; \mathrm{P}=\right.$ $0.003)$. The mean and standard deviation were imputed from the median and interquartile range or $\mathrm{P}$ value from six trials (Barlow 2011; Jones 2013; Lemanu 2013; Lu 2014; Wang 2010; Zhao 2014). The difference in the median hospital stay between enhanced recovery protocols and standard care ranged from one day and five days favouring enhanced recovery protocols (shorter hospital stay in enhanced recovery protocols). Excluding the trials in which mean and standard deviation were imputed did not alter the clinical or statistical significance of the results (MD -2.31 days, 95\% CI -2.93 to -1.69; Analysis 3.2).

\section{Readmissions}

Seven trials (733 participants) reported hospital readmissions ( Jones 2013; Kim 2012; Lemanu 2013; Liu 2010; Lu 2014; Wang 2010; Zhao 2014). There was no statistically significant difference in the proportion of participants requiring hospital readmissions between enhanced recovery protocols and standard care (RR 1.40, 95\% CI 0.69 to 2.87; Analysis 1.8). There was no change in the statistical significance by using the random-effects model. There was no evidence of heterogeneity $\left(\mathrm{I}^{2}=0 \%\right.$; $\left.=0.84\right)$.

\section{Costs}

Four trials (282 participants) reported hospital costs (Kim 2012; Lemanu 2013; Wang 2010; Zhao 2014). The costs were reported in US dollars (USD) in one trial (Kim 2012), New Zealand dollars (NZD) in one trial (Lemanu 2013), and Chinese renminbi (CNY) in two trials (Wang 2010; Zhao 2014). All the currencies were converted to USD using the conversion rates of those currencies on www.xe.com on 2 April 2015. The hospital costs were statistically significantly lower with enhanced recovery protocols than standard care (MD -6300 USD, 95\% CI -8400 to -4200 ; Analysis 1.9). There was no change in the statistical significance by using the random-effects model. There was no evidence of heterogeneity $\left(\mathrm{I}^{2}=12 \% ; \mathrm{P}=0.33\right)$. The mean and standard deviation were imputed from the median and $\mathrm{P}$ value from one trial (Zhao 2014). Excluding this trial did not alter the clinical or statistical significance of the results (MD -6000 USD, 95\% CI 8100 to 3900; Analysis 3.3).

\section{Subgroup analysis}

Of the planned subgroup analysis, we did not perform a subgroup analysis of the different elements of enhanced recovery protocols since there was considerable overlap between the trials in terms of the different elements of enhanced recovery protocols that was incorporated in the intervention arm of the trial (Table 1). None of the trials included children, so we did not perform a subgroup analysis of adults versus children. Amongst the different surgeries, 
only gastrectomy and liver surgery were surgeries that were assessed in two or more trials. We could not obtain the results of the test for subgroup differences for short-term mortality since there was no short-term mortality after gastrectomy in the trials included in the subgroup analysis (Analysis 2.1). The tests for subgroup differences were not statistically significant for proportion or number of serious adverse events. The test for subgroup differences was statistically significant for health-related quality of life $(P=0.01)$ with the enhanced recovery protocol appearing beneficial mainly for liver surgery.

\section{DISCUSSION}

\section{Summary of main results}

In this meta-analysis we found that the proportion of people with mild adverse events, the number of mild adverse events, the length of hospital stay and costs were lower with enhanced recovery protocols compared to standard care after major upper gastrointestinal, liver and pancreatic surgery. There were no statistically significant differences in short-term mortality, the proportion of people with serious adverse events, the number of serious adverse events, short-term health-related quality of life, and the proportion of people requiring readmissions. None of the trials reported longterm mortality, medium-term health-related quality of life, time to return to normal activity or time to return to work.

While mortality and serious adverse events are clinically more important than mild adverse events, an intervention that decreases mild adverse events can be considered useful and can be recommended if it is cost-effective. Enhanced recovery protocols reduced the length of hospital stay and costs. This is important for the vast majority of the healthcare funders, irrespective of whether the healthcare is funded by the state or the patients. On this basis, enhanced recovery protocols appear to be a useful intervention if the evidence is reliable. However, the quality of evidence is low and the effect estimates observed in the trials may not be close to the true effect of the enhanced recovery protocols compared to standard care, as discussed in the section on Quality of the evidence. The test for subgroup differences was statistically significant for quality of life with enhanced recovery protocols demonstrating an improved quality of life in liver surgery, however, there are two notes of caution. The first is that when many subgroup analyses are performed, there is a significant chance of getting spuriously positive results. So, the results of this subgroup analysis have to be interpreted with caution. The second is that we do not know whether the demonstrated increase in the quality of life in liver surgery is clinically significant.

\section{Overall completeness and applicability of evidence}

A variety of surgeries on the oesophagus, stomach, liver and pancreas were included in this review. So, this evidence is applicable in these surgeries. However, it should be noted that only people with good performance status and low anaesthetic risk were included in the trials and so the evidence from this review is applicable only to such people.

\section{Quality of the evidence}

The overall quality of the evidence is low or very low as indicated in Summary of findings for the main comparison. The factors that introduce bias and make the effect estimates unreliable are as follows. One of the major sources of bias in the trials included in this review is the lack of blinding of even the healthcare providers who assess the outcomes, including the adverse events, and make decisions on hospital discharge. Despite the use of specific definitions for adverse events being used for one trial (Barlow 2011), and predefined criteria for hospital discharge for four trials (Barlow 2011; Jones 2013; Liu 2010; Wang 2010), lack of observer blinding can result in bias of these outcomes. This is because adverse events and hospital stay are subjective outcomes since the criteria used for assessment of these outcomes (even if the trials had prespecified criteria) are subjective. Only one trial reported observer blinding for decision on discharge (Jones 2013), while none of the trials used observer blinding for serious adverse events. While it is difficult or even impossible to blind the participants and healthcare providers for some elements of enhanced recovery protocols (preoperative education and early mobilisation), it is possible to blind the outcome assessors for all the elements of enhanced recovery protocols by use of a second surgical team.

Another major source of bias is attrition bias. By excluding participants in whom the protocol was violated or who developed complications intraoperatively, the benefits of enhanced recovery protocols on the length of hospital stay and costs will be overestimated. The length of hospital stay reported in the trials did not include the length of hospital stay during readmissions. This will again overestimate the effect of the enhanced recovery protocol group on the length of hospital stay and costs. If there were no clinically significant differences in the number of people with serious adverse events or readmissions, the effect estimate of the enhanced recovery protocol on the length of hospital stay and costs will be shifted towards null effect. If there were more serious adverse events and readmissions in the enhanced recovery protocols, the balance of benefits and harms of enhanced recovery protocols compared to standard care will again be shifted. Future trials should include all randomised participants and perform an intention-to-treat analysis so that a reasonable estimate of the effect of the enhanced recovery protocol can be obtained and used to guide clinical practice. None of the studies included the organisational 
costs of implementing enhanced recovery protocols. While heterogeneity was noted in some of the outcomes, this was mainly in the magnitude of effect rather than the direction of effect. Heterogeneity appears to be less of a threat to the validity of the results compared to the other factors (lack of blinding of outcome assessors, attrition bias, and the way that the length of hospital stay and costs were measured). However, there is a potential for different effects of enhanced recovery protocols in different surgeries, and so future trials should report the effects of enhanced recovery protocols in different surgeries as subgroups.

\section{Potential biases in the review process}

We performed a thorough literature search using formal search strategies. At least two review authors independently identified trials for inclusion and extracted data, thus minimising errors in these aspects. We examined the influence of our imputations using sensitivity analyses which did not alter the clinical or statistical significance of the results. We were unable to explore publication bias because none of the outcomes had 10 or more trials. However, we searched the trial registers. Since the enhanced recovery protocol is a relatively new intervention, we anticipate that trials related to this topic are registered prospectively. However, four trials are awaiting further assessment (Geubbels 2014; Jin 2013; NCT02348229; Wang 2014), and four trials are currently ongoing (JPRN-UMIN000011572; JPRN-UMIN000014068; NCT01766765; NCT01938313). The inclusion of these trials may alter the conclusions of the review.

\section{Agreements and disagreements with other studies or reviews}

This is the first systematic review to compare enhanced recovery protocols with standard care in people undergoing major upper gastrointestinal, liver and pancreatic surgeries. We identified three systematic reviews with meta-analysis on the role of enhanced recovery protocols versus standard care in people undergoing gastrectomy (Chen 2015; Li 2014; Yu 2014). The authors of these systematic reviews concluded that the length of hospital stay and costs are reduced with enhanced recovery protocols compared to standard care (Chen 2015; Li 2014; Yu 2014). While we observed similar results in our systematic review, we are unable to determine the validity of the results because of the reasons stated in the section on Quality of the evidence.

\section{AUTHORS' CONCLUSIONS}

\section{Implications for practice}

Based on low quality evidence, enhanced recovery protocols may reduce the length of hospital stay and hospital costs (primarily because of reduction in hospital stay) in people undergoing major upper gastrointestinal, liver and pancreatic surgeries. However, the validity of the results is uncertain because of the risk of bias in the trials and the way the outcomes were measured.

\section{Implications for research}

Future RCTs should use appropriate randomisation methods, use outcome assessor blinding, include all randomised participants, and measure clinical outcomes such as mortality, morbidity, health-related quality of life and length of hospital stay (including any readmissions for procedure related complications) for at least three months to one year to determine the utility of enhanced recovery protocols on people undergoing major upper gastrointestinal, liver and pancreatic surgeries. Since the impact of enhanced recovery protocols may be different between different surgeries, the results of different surgeries should be reported separately as subgroup analyses.

\section{ACKNOW LEDGEMENTS}

We thank Karin Dearness, Managing Editor, Cochrane Upper Gastrointestinal and Pancreatic Diseases (UGPD) Group, for providing administrative and logistical support for the conduct of the current review.

We thank the copy editors and the Cochrane Editorial Unit for their comments. 


\section{R E F E R E N C E S}

\section{References to studies included in this review}

Barlow 2011 \{published data only\}

Barlow R, Price P, Reid TD, Hunt S, Clark GW, Havard TJ, et al. Prospective multicentre randomised controlled trial of early enteral nutrition for patients undergoing major upper gastrointestinal surgical resection. Clinical Nutrition 2011; 30(5):560-6.

Jones 2013 \{published data only\}

Jones C, Kelliher L, Dickinson M, Riga A, Worthington T, Scott MJ, et al. Randomized clinical trial on enhanced recovery versus standard care following open liver resection. British Journal of Surgery 2013;100(8):1015-24.

Jones C, Kelliher L, Scott M, Dickinson M, Karajia N. Enhanced recovery in liver resection surgery: a singleblinded randomised controlled trial. British Journal of Anaesthesia 2012;108(Suppl 2):ii242-3.

Kim 2012 \{published data only\}

Kim JW, Kim WS, Cheong JH, Hyung WJ, Choi SH, Noh $\mathrm{SH}$. Safety and efficacy of fast-track surgery in laparoscopic distal gastrectomy for gastric cancer: a randomized clinical trial. World Journal of Surgery 2012;36(12):2879-87.

Lemanu 2013 \{published data only\}

Lemanu DP, Singh PP, Berridge K, Burr M, Birch C, Babor $\mathrm{R}$, et al. Randomized clinical trial of enhanced recovery versus standard care after laparoscopic sleeve gastrectomy. British Journal of Surgery 2013;100(4):482-9.

Liu 2010 \{published data only\}

Liu XX, Jiang ZW, Wang ZM, Li JS. Multimodal optimization of surgical care shows beneficial outcome in gastrectomy surgery. Journal of Parenteral and Enteral Nutrition 2010;34(3):313-21.

Lu 2014 \{published data only\}

Lu H, Fan Y, Zhang F, Li GQ, Zhang CY, Lu L, et al. Fast-track surgery improves postoperative outcomes after hepatectomy. Hepatogastroenterology 2014;61(129):168-72.

Miyachi 2013 \{published data only\}

Miyachi T, Oyama A, Tsuchiya T, Abe N, Sato A, Chiba $Y$, et al. Perioperative oral administration of cystine and theanine enhances recovery after distal gastrectomy: A prospective randomized trial. Journal of Parenteral and Enteral Nutrition 2013;37(3):384-91.

Ni 2013 \{published data only\} Ni CY, Yang Y, Chang YQ, Cai H, Xu B, Yang F, et al. Fasttrack surgery improves postoperative recovery in patients undergoing partial hepatectomy for primary liver cancer: A prospective randomized controlled trial. European Journal of Surgical Oncology 2013;39(6):542-7.

Wang 2010 \{published data only\} Wang D, Kong Y, Zhong B, Zhou X, Zhou Y. Fast-track surgery improves postoperative recovery in patients with gastric cancer: a randomized comparison with conventional postoperative care. Journal of Gastrointestinal Surgery 2010; 14(4):620-7.
Zhao 2014 \{published data only\}

Zhao G, Cao S, Cui J. Fast-track surgery improves postoperative clinical recovery and reduces postoperative insulin resistance after esophagectomy for esophageal cancer. Supportive Care in Cancer 2014;22(2):351-8.

\section{References to studies excluded from this review}

Cheifetz 2010 \{published data only\}

Cheifetz O, Lucy SD, Overend TJ, Crowe J. The Effect of abdominal support on functional outcomes in patients following major abdominal surgery: a randomized controlled trial. Physiotherapy Canada 2010;62(3):242-53.

Dejong 2014 \{published data only\}

Dejong CHC, van Dam RM. Enhanced recovery programs in liver surgery. World Journal of Surgery 2014;38(10): 2683-4.

Feldman 2014 \{published data only\}

Feldman LS, Delaney CP. Laparoscopy plus enhanced recovery: optimizing the benefits of MIS through SAGES 'SMART' program. Surgical Endoscopy 2014;28(5):1403-6.

Gillissen 2011 \{published data only\} Gillissen F, Coolsen MME, Van Dam RM, Bemelmans $\mathrm{MH}$, Damink SWO, Malago M, et al. Optimised recovery with magnesium oxide after liver resection. A randomised controlled trial. HPB 2011;13:80.

Hendry 2010 \{published data only\} Hendry PO, van Dam RM, Bukkems S, McKeown DW, Parks RW, Preston T, et al. Randomized clinical trial of laxatives and oral nutritional supplements within an enhanced recovery after surgery protocol following liver resection. British Journal of Surgery 2010;97(8):1198-206.

Hubner 2012 \{published data only\}

Hubner M, Cerantola Y, Grass F, Bertrand PC, Schafer M, Demartines N. Preoperative immunonutrition in patients at nutritional risk: results of a double-blinded randomized clinical trial. European Journal of Clinical Nutrition 2012;66 (7):850-5.

Revie 2012 \{published data only\} Revie EJ, McKeown DW, Wilson JA, Garden OJ, Wigmore SJ. Randomized clinical trial of local infiltration plus patient-controlled opiate analgesia vs. epidural analgesia following liver resection surgery. HPB (Oxford) 2012;14(9): 611-8.

Sahoo 2014 \{published data only\} Sahoo MR, Gowda MS, Kumar AT. Early rehabilitation after surgery program versus conventional care during perioperative period in patients undergoing laparoscopic assisted total gastrectomy. Journal of Minimal Access Surgery 2014;10(3):132-8.

Serclova 2009 \{published data only\} Serclova Z, Dytrych P, Marvan J, Nova K, Hankeova $Z$, Ryska $O$, et al. Fast-track in open intestinal surgery: Prospective randomized study (Clinical Trials Gov Identifier 
no. NCT00123456). Clinical Nutrition 2009;28(6):

618-24.

Strobel 2013 \{published data only\}

Strobel O, Buchler MW. Superior results after fast track recovery versus standard care following liver resection: Results of a randomized clinical trial. Der Chirurg 2013;84 (9):800.

Wattchow 2009 \{published data only\}

Wattchow DA, De Fontgalland D, Bampton PA, Leach PL, McLaughlin K, Costa M. Clinical trial: the impact of cyclooxygenase inhibitors on gastrointestinal recovery after major surgery - a randomized double blind controlled trial of celecoxib or diclofenac vs. placebo. Alimentary Pharmacology and Therapeutics 2009;30(10):987-98.

\section{References to studies awaiting assessment}

Geubbels 2014 \{published data only\}

Geubbels N, Evren I, Hoen MB, Acherman YI, Bruin SC, van de Laar AW, et al. Fast track in laparoscopic Roux-en$Y$ gastric bypass surgery enhances recovery: results from a prospective, randomized, controlled single centre study. Obesity Surgery 2014;24(8):1141.

Jin 2013 \{published data only\} Jin G, Shao Z, Ma HY, Ou Y, Song B, Hu XG. Fast-track recovery after pancreatoduodenectomy: A prospective randomized controlled study. $H P B$ 2013;15:74.

NCT02348229 \{published data only\}

NCT02348229. Effect of enhanced recovery after surgery (ERAS) on C-reactive and visceral proteins (ERASAG). clinicaltrials.gov/show/NCT02348229 (accessed 4 April 2015).

Wang 2014 \{published data only\}

Wang G, Yang Y, Zhou B, Chen Y, Jin C, Wang Z, et al. Promotion of postoperative recovery with fast track surgery for gastric cancer patients undergoing gastrectomy: a prospective randomized controlled study. Zhonghua Weichang Waike Zazhi 2014;17(5):489-91.

\section{References to ongoing studies}

\section{JPRN-UMIN000011572 \{published data only\}}

JPRN-UMIN000011572. Randomized clinical trial on the efficacy and safety of perioperative management using ERAS protocol in gastric cancer. upload.umin.ac.jp/cgiopen-bin $/ \mathrm{ctr} / \mathrm{ctr}$.cgi?function=brows\&action=brows\&type= summary\&recptno=R000013534\&language $=\mathrm{E}$ (accessed 4 April 2015).

JPRN-UMIN000014068 \{published data only\} JPRN-UMIN000014068. Randomized clinical trial of an enhanced recovery after surgery protocol in patients undergoing pancreaticoduodenectomy. upload.umin.ac.jp/ cgi-open-bin/ctr/ctr.cgi?function=brows\&action=brows \& type $=$ summary\&recptno $=$ R000016216\&language $=E$ (accessed 4 April 2015).

\section{NCT01766765 \{published data only\}}

NCT01766765. Early jejunostomy nutrition minimizes time to chemotherapy. clinicaltrials.gov/show/ NCT01766765 (accessed 4 April 2015).

\section{NCT01938313 \{published data only\}} NCT01938313. Early recovery after surgery (ERAS) versus conventional protocol after laparoscopic gastrectomy. clinicaltrials.gov/show/NCT01938313 accessed 4 April 2015).

\section{Additional references}

\section{BADS 2012}

BADS Directory of Procedures (4th Edition), 2012. daysurgeryuk.net/en/shop/publications/bads-directory-ofprocedures-4th-edition/ (accessed 13 November 2014).

\section{Chen 2015}

Chen S, Zou Z, Chen F, Huang Z, Li G. A meta-analysis of fast track surgery for patients with gastric cancer undergoing gastrectomy. Annals of the Royal College of Surgeons of England 2015;97(1):3-10.

\section{Clavien 2009}

Clavien PA, Barkun J, de Oliveira ML, Vauthey JN, Dindo D, Schulick RD, et al. The Clavien-Dindo classification of surgical complications: five-year experience. Annals of Surgery 2009;250(2):187-96.

Demets 1987

Demets DL. Methods for combining randomized clinical trials: strengths and limitations. Statistics in Medicine 1987; 6(3):341-50.

\section{DerSimonian 1986}

DerSimonian R, Laird N. Meta-analysis in clinical trials. Controlled Clinical Trials 1986;7(3):177-88.

Dindo 2004

Dindo D, Demartines N, Clavien PA. Classification of surgical complications: a new proposal with evaluation in a cohort of 6336 patients and results of a survey. Annals of Surgery 2004;240(2):205-13.

Egger 1997

Egger M, Davey SG, Schneider M, Minder C. Bias in metaanalysis detected by a simple, graphical test. BMJ (Clinical Research Edition) 1997;315(7109):629-34.

GRADEproGDT 2015 [Computer program] McMaster University (developed by Evidence Prime, Inc.). GRADEproGDT: GRADEpro Guideline Development Tool [www.guidelinedevelopment.org]. Hamilton: McMaster University (developed by Evidence Prime, Inc.), 2015.

\section{Higgins 2011}

Higgins JPT, Green S (editors). Cochrane Handbook for Systematic Reviews of Interventions Version 5.1.0 [updated March 2011]. The Cochrane Collaboration, 2011. Available from www.cochrane-handbook.org.

\section{Hospital Episode Statistics 2013}

Health and Social Information Provider. Hospital Episode Statistics, Admitted Patient Care, England: 2012-13. http:// 
www.hscic.gov.uk/searchcatalogue? productid $=13264 \& q=t i-$ tle\%3a\%22Hospital+Episode+Statistics\%2c+Admitted+patient+care++England\%22\&sort=Relevance\&size $=10 \&$ page $=1 \#$ top (accessed 13 November 2014).

\section{ICH-GCP 1996}

International Conference on Harmonisation of Technical Requirements for Registration of Pharmaceuticals for Human Use. Code of Federal Regulation \& ICH Guidelines. Media: Parexel Barnett, 1996.

\section{Kehlet 1997}

Kehlet H. Multimodal approach to control postoperative pathophysiology and rehabilitation. British Journal of Anaesthesia 1997;78(5):606-17.

\section{Li 2014}

Li YJ, Huo TT, Xing J, An JZ, Han ZY, Liu XN, et al. Meta-analysis of efficacy and safety of fast-track surgery in gastrectomy for gastric cancer. World Journal of Surgery 2014;38(12):3142-51.

\section{Moher 2009}

Moher D, Liberati A, Tetzlaff J, Altman DG, The PRISMA
Group. Preferred reporting items for systematic reviews and meta-analyses: The PRISMA Statement. BMJ 2009;339: 2535 .

\section{Parmar 1998}

Parmar MK, Torri V, Stewart L. Extracting summary statistics to perform meta-analyses of the published literature for survival endpoints. Statistics in Medicine 1998;17(24): 2815-34.

\section{RevMan 2014 [Computer program]}

The Nordic Cochrane Centre, The Cochrane Collaboration. Review Manager (RevMan). Version 5.3. Copenhagen: The Nordic Cochrane Centre, The Cochrane Collaboration, 2014.

\section{Yu 2014}

Yu Z, Zhuang CL, Ye XZ, Zhang CJ, Dong QT, Chen BC. Fast-track surgery in gastrectomy for gastric cancer: a systematic review and meta-analysis. Langenbeck's Archives of Surgery 2014;399(1):85-92.

* Indicates the major publication for the study 


\section{CHARACTERISTICS OF STUDIES}

\section{Characteristics of included studies [ordered by study ID]}

\section{Barlow 2011}

\begin{tabular}{|c|c|}
\hline Methods & Randomised controlled trial \\
\hline Participants & $\begin{array}{l}\text { Country: UK. } \\
\text { Number randomised: } 121 \\
\text { Post-randomisation drop-outs: } 0(0 \%) \\
\text { Revised sample size: } 121 \\
\text { Average age: } 64 \text { years } \\
\text { Females: } 38(31.4 \%) \\
\text { Inclusion criteria } \\
\text { 1. All adult patients admitted with a suspected upper gastrointestinal malignancy and } \\
\text { referred for major elective surgery (oesophagectomy, gastrectomy and pancreatectomy) } \\
\text { Exclusion criteria } \\
\text { 1. Age under } 18 \text { years } \\
\text { 2. Unable or unwilling to give informed consent } \\
\text { 3. Pregnancy } \\
\text { 4. Preoperative infection } \\
5 \text {. Previous intestinal surgery resulting in residual small intestine length of less than } \\
100 \mathrm{~cm}\end{array}$ \\
\hline
\end{tabular}

Interventions

Participants were randomly assigned to two groups

Group 1: enhanced recovery protocol $(n=64)$

Further details: Early enteral nutrition delivered via a needle catheter jejunostomy

Group 2: standard care $(\mathrm{n}=57)$

Outcomes

The outcomes reported were short-term mortality, serious adverse events, mild adverse events and length of hospital stay

Notes

Risk of bias

\begin{tabular}{|c|c|c|}
\hline Bias & Authors' judgement & Support for judgement \\
\hline $\begin{array}{l}\text { Random sequence generation (selection } \\
\text { bias) }\end{array}$ & Low risk & $\begin{array}{l}\text { Quote: "Randomisation was stratified within each cen- } \\
\text { tre, and the randomisation sequence was generated by } \\
\text { computer in permuted blocks of } 30 \text { " }\end{array}$ \\
\hline
\end{tabular}

Allocation concealment (selection bias) Low risk

Quote: "The code was kept in opaque, sealed envelopes labelled with sequential study numbers in a locked box at the co-ordinating research site"

Blinding of participants and personnel High risk (performance bias)

Quote: "This was an unblinded study"

All outcomes

Enhanced recovery protocols for major upper gastrointestinal, liver and pancreatic surgery (Review) 
Barlow 2011 (Continued)

\begin{tabular}{|c|c|c|}
\hline $\begin{array}{l}\text { Blinding of outcome assessment (detection } \\
\text { bias) } \\
\text { All outcomes }\end{array}$ & High risk & Quote: "This was an unblinded study" \\
\hline $\begin{array}{l}\text { Incomplete outcome data (attrition bias) } \\
\text { All outcomes }\end{array}$ & Low risk & Comment: There were no post-randomisation drop-outs \\
\hline Selective reporting (reporting bias) & Low risk & Comment: All important outcomes were reported \\
\hline Other bias & Low risk & $\begin{array}{l}\text { Quote: "The trial was funded by grant to Dr Barlow: } \\
\text { "Leading Practice through research" from the The Health } \\
\text { Foundation, London, UK" }\end{array}$ \\
\hline
\end{tabular}

Jones 2013

\begin{tabular}{|c|c|}
\hline Methods & Randomised controlled trial \\
\hline Participants & $\begin{array}{l}\text { Country: UK. } \\
\text { Number randomised: } 104 \\
\text { Post-randomisation drop-outs: } 13(12.5 \%) \\
\text { Revised sample size: } 91 \\
\text { Average age: } 66 \text { years } \\
\text { Females: } 37(40.7 \%) \\
\text { Inclusion criteria } \\
\text { All patients presenting for open liver surgery } \\
\text { Exclusion criteria } \\
\text { 1. Operation was entirely laparoscopic } \\
\text { 2. Patient needed a second concomitant procedure (e.g. bile duct repair) } \\
\text { 3. Found to be inoperable. } \\
\text { 4. Unable to consent }\end{array}$ \\
\hline Interventions & $\begin{array}{l}\text { Participants were randomly assigned to two groups } \\
\text { Group 1: enhanced recovery protocol }(\mathrm{n}=46) \\
\text { Further details: } \\
\text { Preoperatively: education } \\
\text { Postoperatively: early mobilisation and early oral feeding according to a specific schedule } \\
\text { Group 2: standard care }(\mathrm{n}=45)\end{array}$ \\
\hline Outcomes & $\begin{array}{l}\text { The outcomes reported were short-term mortality, serious adverse events, health-related } \\
\text { quality of life, mild adverse events, length of hospital stay and readmissions }\end{array}$ \\
\hline Notes & $\begin{array}{l}\text { Authors provided additional information in January } 2015 \\
\text { Reasons for post-randomisation drop-outs: } 13 \text { due to changes in their oncological staging } \\
\text { (they either underwent additional procedures, were inoperable at the time of surgery, or } \\
\text { had a laparoscopic resection) }\end{array}$ \\
\hline
\end{tabular}

Risk of bias

Enhanced recovery protocols for major upper gastrointestinal, liver and pancreatic surgery (Review) 
Jones 2013 (Continued)

\begin{tabular}{|c|c|c|}
\hline Bias & Authors' judgement & Support for judgement \\
\hline $\begin{array}{l}\text { Random sequence generation (selection } \\
\text { bias) }\end{array}$ & Low risk & $\begin{array}{l}\text { Quote: "The randomization sequence of group allocation } \\
\text { by means of brown opaque envelopes was generated by an } \\
\text { independent statistician from the University of Surrey" }\end{array}$ \\
\hline Allocation concealment (selection bias) & Low risk & $\begin{array}{l}\text { Quote: "The randomization sequence of group allocation } \\
\text { by means of brown opaque envelopes was generated by an } \\
\text { independent statistician from the University of Surrey" }\end{array}$ \\
\hline $\begin{array}{l}\text { Blinding of participants and personnel } \\
\text { (performance bias) } \\
\text { All outcomes }\end{array}$ & High risk & $\begin{array}{l}\text { Quote: “no blinding” } \\
\text { Comment: email reply }\end{array}$ \\
\hline $\begin{array}{l}\text { Blinding of outcome assessment (detection } \\
\text { bias) } \\
\text { All outcomes }\end{array}$ & High risk & $\begin{array}{l}\text { Quote: "only assessor for fitness for discharge was } \\
\text { blinded, meaning Length of stay was blinded" } \\
\text { Comment: email reply }\end{array}$ \\
\hline $\begin{array}{l}\text { Incomplete outcome data (attrition bias) } \\
\text { All outcomes }\end{array}$ & High risk & $\begin{array}{l}\text { Quote: "Thirteen patients were withdrawn after random- } \\
\text { ization because of changes to their original oncological } \\
\text { staging" }\end{array}$ \\
\hline Selective reporting (reporting bias) & Low risk & Comment: All important outcomes were reported \\
\hline Other bias & Low risk & $\begin{array}{l}\text { Quote: "Thanks also go to GUTS (Guildford Undetected } \\
\text { Tumour Screening) and LCSA (Liver Cancer Surgery } \\
\text { Appeal) charities who kindly provided grants helping to } \\
\text { fund the trial" }\end{array}$ \\
\hline
\end{tabular}

$\operatorname{Kim} 2012$

\begin{tabular}{l|l}
\hline Methods & Randomised controlled trial \\
\hline Participants & Country: Korea \\
& Number randomised: 47 \\
& Post-randomisation drop-outs: $3(6.4 \%)$ \\
& Revised sample size: 44 \\
Average age: 55 years & Females: $16(36.4 \%)$ \\
Inclusion criteria & 1. Gastric cancer that could be treated with a laparoscopic distal gastrectomy \\
& 2. Pathological confirmation of gastric adenocarcinoma \\
& 3. Preoperative cancer stage of $\mathrm{T}_{1} \mathrm{~N}_{0} \mathrm{M}_{0}, \mathrm{~T}_{1} \mathrm{~N}_{1} \mathrm{M}_{0}$ or $\mathrm{T}_{2} \mathrm{~N}_{0} \mathrm{M}_{0}$ \\
4. Location of the lesion in the lower half of the stomach & Exclusion criteria \\
Factors that might impede a fast recovery: \\
1. pregnancy \\
2. inflammatory bowel disease
\end{tabular}

Enhanced recovery protocols for major upper gastrointestinal, liver and pancreatic surgery (Review) 
Kim 2012 (Continued)
3. chronic renal disease
4. chronic liver disease
5. cardiopulmonary dysfunction
6. complicated diabetes
7. the use of anticholinergic medications
8. ASA (The American Society of Anaesthesiologists) $>2$
9. ECOG (Eastern Cooperative Oncology Group performance status) grade $>3$

Participants were randomly assigned to two groups
Group 1: enhanced recovery protocol $(\mathrm{n}=22)$
Further details:
Preoperatively: education
Postoperatively: pain relief, early mobilisation and early oral feeding according to a
specific schedule
Group 2: standard care $(\mathrm{n}=22)$

Outcomes

The outcomes reported were short-term mortality, serious adverse events, health-related quality of life, mild adverse events, length of hospital stay, readmissions and costs

Notes

Reasons for post-randomisation drop-outs: protocol violation (1); surgeon suspected an insecure anastomosis (2) - both developed anastomotic stricture and required endoscopic stenting postoperatively

\section{Risk of bias}

\begin{tabular}{|c|c|c|}
\hline Bias & Authors' judgement & Support for judgement \\
\hline $\begin{array}{l}\text { Random sequence generation (selection } \\
\text { bias) }\end{array}$ & Low risk & $\begin{array}{l}\text { Quote: "Randomisation was performed by drawing lots } \\
\text { under stratification for gender by the co-ordinator" }\end{array}$ \\
\hline Allocation concealment (selection bias) & Low risk & $\begin{array}{l}\text { Quote: "Randomisation was performed by drawing lots } \\
\text { under stratification for gender by the co-ordinator" }\end{array}$ \\
\hline $\begin{array}{l}\text { Blinding of participants and personnel } \\
\text { (performance bias) } \\
\text { All outcomes }\end{array}$ & High risk & $\begin{array}{l}\text { Quote: "The nurses and physicians were told the result } \\
\text { of the randomisation" }\end{array}$ \\
\hline $\begin{array}{l}\text { Blinding of outcome assessment (detection } \\
\text { bias) } \\
\text { All outcomes }\end{array}$ & High risk & $\begin{array}{l}\text { Quote: "The nurses and physicians were told the result } \\
\text { of the randomisation" }\end{array}$ \\
\hline $\begin{array}{l}\text { Incomplete outcome data (attrition bias) } \\
\text { All outcomes }\end{array}$ & High risk & Comment: There were post-randomisation drop-outs \\
\hline Selective reporting (reporting bias) & Low risk & Comment: All important outcomes were reported \\
\hline Other bias & High risk & $\begin{array}{l}\text { Quote: "The LAPD was supplied from B. Braun Korea } \\
\text { Company just for this study" }\end{array}$ \\
\hline
\end{tabular}




\begin{tabular}{ll}
\hline Methods & Randomised controlled trial \\
\hline Participants & Country: New Zealand. \\
& Number randomised: 106 \\
& Post-randomisation drop-outs: 28 (26.4\%) \\
& Revised sample size: 78 \\
& Average age: 44 years \\
& Females: 55 (70.5\%) \\
& Inclusion criteria \\
& All patients offered laparoscopic sleeve gastrectomy \\
& Exclusion criteria \\
& Patients having LSG as a revisional bariatric procedure \\
\hline Interventions & Participants were randomly assigned to two groups \\
& Group $1:$ enhanced recovery protocol (n $=40)$ \\
& Further details: \\
& Preoperatively: education \\
Postoperatively: pain relief, early mobilisation and early oral feeding according to a \\
specific schedule \\
Group 2: standard care (n = 38) \\
\hline
\end{tabular}

Outcomes

The outcomes reported were short-term mortality, serious adverse events, mild adverse events, mild adverse events, length of hospital stay and readmissions

Notes

Reasons for post-randomisation drop-outs: Surgery changed to another site or cancelled or other miscellaneous reasons

\section{Risk of bias}

\begin{tabular}{l|l|l} 
Bias & Authors' judgement & Support for judgement \\
\hline $\begin{array}{l}\text { Random sequence generation (selection } \\
\text { bias) }\end{array}$ & Low risk & $\begin{array}{l}\text { Quote: "Randomization was performed by an indepen- } \\
\text { dent researcher not involved in patient recruitment or } \\
\text { outcome assessment using a computerized random-num- } \\
\text { ber generator" }\end{array}$ \\
\hline Allocation concealment (selection bias) & Low risk & $\begin{array}{l}\text { Quote: “Group allocations were placed in sequentially } \\
\text { numbered opaque sealed envelopes" }\end{array}$
\end{tabular}

Blinding of participants and personnel Unclear risk

Comment: This information was not available (performance bias)

All outcomes

Blinding of outcome assessment (detection Unclear risk bias)

All outcomes

Incomplete outcome data (attrition bias) High risk

Comment: There were post-randomisation drop-outs All outcomes

Enhanced recovery protocols for major upper gastrointestinal, liver and pancreatic surgery (Review) 
Lemanu 2013 (Continued)

\begin{tabular}{|c|c|c|}
\hline Selective reporting (reporting bias) & High risk & Comment: Complications were not reported adequately \\
\hline Other bias & Low risk & $\begin{array}{l}\text { Quote: "This study required no external sources of fund- } \\
\text { ing" }\end{array}$ \\
\hline
\end{tabular}

Liu 2010

\begin{tabular}{|c|c|c|}
\hline Methods & \multicolumn{2}{|c|}{ Randomised controlled trial } \\
\hline Participants & \multicolumn{2}{|c|}{$\begin{array}{l}\text { Country: China } \\
\text { Number randomised: } 63 \\
\text { Post-randomisation drop-outs: } 0(0 \%) \\
\text { Revised sample size: } 63 \\
\text { Average age: } 61 \text { years } \\
\text { Females: } 29(46 \%) \\
\text { Inclusion criteria } \\
\text { Patients undergoing gastrectomy for gastric cancer } \\
\text { Exclusion criteria } \\
\text { 1. Patients with reluctance to discharge early } \\
\text { 2. Presence of other organ dysfunction such as lung and kidney } \\
\text { 3. Abnormal clinical test results } \\
\text { 4. Preoperative chemotherapy } \\
\text { 5. Preoperative radiotherapy }\end{array}$} \\
\hline Interventions & \multicolumn{2}{|c|}{$\begin{array}{l}\text { Participants were randomly assigned to two groups } \\
\text { Group 1: enhanced recovery protocol }(\mathrm{n}=33) \\
\text { Further details: } \\
\text { Postoperatively: early mobilisation and early oral feeding } \\
\text { Group 2: standard care }(\mathrm{n}=30)\end{array}$} \\
\hline Outcomes & \multicolumn{2}{|c|}{$\begin{array}{l}\text { The outcomes reported were short-term mortality, serious adverse events, mild adverse } \\
\text { events, length of hospital stay and readmissions }\end{array}$} \\
\hline \multicolumn{3}{|l|}{ Notes } \\
\hline \multicolumn{3}{|l|}{ Risk of bias } \\
\hline Bias & Authors' judgement & Support for judgement \\
\hline $\begin{array}{l}\text { Random sequence generation (selection } \\
\text { bias) }\end{array}$ & Unclear risk & Comment: This information was not available \\
\hline Allocation concealment (selection bias) & Unclear risk & $\begin{array}{l}\text { Quote: "Randomization was performed using opaque } \\
\text { sealed envelopes" } \\
\text { Comment: Further details were not available }\end{array}$ \\
\hline
\end{tabular}




\section{Liu 2010 (Continued)}

\begin{tabular}{|c|c|c|}
\hline $\begin{array}{l}\text { Blinding of participants and personnel } \\
\text { (performance bias) } \\
\text { All outcomes }\end{array}$ & High risk & $\begin{array}{l}\text { Quote: "As with other fast-track trials, it was not possible } \\
\text { to blind this study" }\end{array}$ \\
\hline $\begin{array}{l}\text { Blinding of outcome assessment (detection } \\
\text { bias) } \\
\text { All outcomes }\end{array}$ & High risk & $\begin{array}{l}\text { Quote: "As with other fast-track trials, it was not possible } \\
\text { to blind this study" }\end{array}$ \\
\hline $\begin{array}{l}\text { Incomplete outcome data (attrition bias) } \\
\text { All outcomes }\end{array}$ & High risk & Comment: There were post-randomisation drop-outs \\
\hline Selective reporting (reporting bias) & High risk & Comment: Complications were not reported adequately \\
\hline Other bias & Unclear risk & $\begin{array}{l}\text { Comment: Information on source of funding was not } \\
\text { available }\end{array}$ \\
\hline
\end{tabular}

\section{Lu 2014}

Methods

\section{Participants}

Interventions

Outcomes

Notes
Randomised controlled trial

Country: China.

Number randomised: 297

Post-randomisation drop-outs: not stated

Revised sample size: 297

Average age: 53 years

Females: 53 (17.8\%)

\section{Inclusion criteria}

1. Patients with hepatocellular carcinoma (diagnosed and pathologically confirmed) undergoing surgery

2. Preoperative assessment suggested no existing physical illness, Child Pugh grade of $\mathrm{A}$ or $\mathrm{B}$, no tumour metastasis and limited partial liver resection

3. No preoperative or intraoperative transcatheter hepatic arterial chemoembolisation or radiofrequency ablation

4. Tumour completely resected

Participants were randomly assigned to two groups

Group 1: enhanced recovery protocol $(\mathrm{n}=135)$

Further details:

Postoperatively: early mobilisation and early oral feeding

Group 2: standard care $(\mathrm{n}=162)$

The outcomes reported were short-term mortality, serious adverse events, mild adverse events, length of hospital stay and readmissions

\section{Risk of bias}


Lu 2014 (Continued)

\begin{tabular}{|c|c|c|}
\hline Bias & Authors' judgement & Support for judgement \\
\hline $\begin{array}{l}\text { Random sequence generation (selection } \\
\text { bias) }\end{array}$ & Unclear risk & Comment: This information was not available \\
\hline Allocation concealment (selection bias) & Unclear risk & Comment: This information was not available \\
\hline $\begin{array}{l}\text { Blinding of participants and personnel } \\
\text { (performance bias) } \\
\text { All outcomes }\end{array}$ & Unclear risk & $\begin{array}{l}\text { Quote: "This trial was randomized and single-blinded" } \\
\text { Comment: The group that was blinded was not stated }\end{array}$ \\
\hline $\begin{array}{l}\text { Blinding of outcome assessment (detection } \\
\text { bias) } \\
\text { All outcomes }\end{array}$ & Unclear risk & $\begin{array}{l}\text { Quote: "This trial was randomized and single-blinded" } \\
\text { Comment: The group that was blinded was not stated }\end{array}$ \\
\hline $\begin{array}{l}\text { Incomplete outcome data (attrition bias) } \\
\text { All outcomes }\end{array}$ & Unclear risk & Comment: This information was not available \\
\hline Selective reporting (reporting bias) & High risk & Comment: Complications were not reported adequately \\
\hline Other bias & Unclear risk & $\begin{array}{l}\text { Comment: Information on source of funding was not } \\
\text { available }\end{array}$ \\
\hline
\end{tabular}

\section{Miyachi 2013}

\begin{tabular}{|c|c|}
\hline Methods & Randomised controlled trial \\
\hline Participants & $\begin{array}{l}\text { Country: Japan } \\
\text { Number randomised: } 43 \\
\text { Post-randomisation drop-outs: } 10(23.3 \%) \\
\text { Revised sample size: } 33 \\
\text { Average age: } 60 \text { years } \\
\text { Females: } 13(39.4 \%) \\
\text { Inclusion criteria } \\
\text { All patients aged } 40 \text { to } 75 \text { who underwent distal gastrectomy for gastric cancer } \\
\text { Exclusion criteria } \\
\text { 1. Distant metastases } \\
\text { 2. Undernutrition (serum albumin }<3.5 \text { g.dL) } \\
\text { 3. Decline in performance status (greater than or equal to } 2) \\
\text { 4. Pyloric stenosis for cancer }\end{array}$ \\
\hline Interventions & $\begin{array}{l}\text { Participants were randomly assigned to two groups } \\
\text { Group 1: enhanced recovery protocol }(\mathrm{n}=15) \\
\text { Further details: Cystine ( } 700 \mathrm{mg}) \text { and Theanine }(280 \mathrm{mg}) \text { administered orally to patients } \\
\text { with a small amount of water from } 4 \text { days before surgery to } 5 \text { days after surgery, including } \\
\text { the day of the procedure } \\
\text { Group 2: standard care }(\mathrm{n}=18)\end{array}$ \\
\hline
\end{tabular}


Miyachi 2013 (Continued)

\begin{tabular}{ll}
\hline Outcomes & None of the outcomes of interest were reported \\
\hline Notes & $\begin{array}{l}\text { Reasons for post-randomisation drop-outs: Onset of herpes zoster before the procedure } \\
(1), \text { excessive intraoperative haemorrhage }(>600 \mathrm{~mL})(2), \text { injury to the left hepatic } \\
\text { artery during surgery }(1), \text { changes in surgical procedure }(2), \text { metastasis to the peritoneum } \\
\text { confirmed during surgery (1) and withdrawal of consent (3) }\end{array}$ \\
\hline
\end{tabular}

Risk of bias

\begin{tabular}{|c|c|c|}
\hline Bias & Authors' judgement & Support for judgement \\
\hline $\begin{array}{l}\text { Random sequence generation (selection } \\
\text { bias) }\end{array}$ & Unclear risk & Comment: This information was not available \\
\hline Allocation concealment (selection bias) & Unclear risk & $\begin{array}{l}\text { Quote: "Patients were assigned to } 1 \text { of } 2 \text { groups using } \\
\text { the sealed- envelope method and a randomized, single- } \\
\text { blind, parallel- group study was performed" } \\
\text { Comment: Further details were not available }\end{array}$ \\
\hline $\begin{array}{l}\text { Blinding of participants and personnel } \\
\text { (performance bias) } \\
\text { All outcomes }\end{array}$ & Unclear risk & $\begin{array}{l}\text { Quote: "Patients were assigned to } 1 \text { of } 2 \text { groups using } \\
\text { the sealed- envelope method and a randomized, single- } \\
\text { blind, parallel- group study was performed" } \\
\text { Comment: This trial states single blinding and a placebo } \\
\text { was used but it is not clear who was blinded }\end{array}$ \\
\hline $\begin{array}{l}\text { Blinding of outcome assessment (detection } \\
\text { bias) } \\
\text { All outcomes }\end{array}$ & Unclear risk & $\begin{array}{l}\text { Quote: "Patients were assigned to } 1 \text { of } 2 \text { groups using } \\
\text { the sealed- envelope method and a randomized, single- } \\
\text { blind, parallel-group study was performed" } \\
\text { Comment: This trial states single blinding and a placebo } \\
\text { was used but it is not clear who was blinded }\end{array}$ \\
\hline $\begin{array}{l}\text { Incomplete outcome data (attrition bias) } \\
\text { All outcomes }\end{array}$ & High risk & Comment: There were post-randomisation drop-outs \\
\hline Selective reporting (reporting bias) & High risk & Comment: Complications were not reported adequately \\
\hline Other bias & Unclear risk & $\begin{array}{l}\text { Comment: Information on source of funding was not } \\
\text { available }\end{array}$ \\
\hline
\end{tabular}

\section{Ni 2013}

\begin{tabular}{ll}
\hline Methods & Randomised controlled trial \\
\hline Participants & Country: China \\
& Number randomised: 160 \\
& Post-randomisation drop-outs: $0(0 \%)$ \\
& Revised sample size: 160 \\
& Average age: 49 years
\end{tabular}


Females: 35 (21.9\%)

Inclusion criteria

1. Elective partial hepatectomy for liver cancer

2. No major surgical concomitant surgical procedures such as a bowel or bile duct resection

3. Tumours either in the right or left hemiliver with the extent of partial hepatectomy being a hemihepatectomy or less

4. Child-Pugh Class A/B liver functional status

\section{Exclusion criteria}

1. Age less than 16 or over 65

2. Benign liver tumour or metastatic liver cancer

3. Severe concomitant medical disease

4. Combined with other surgery

5. Liver re-resection

6. Bilobar tumour

7. Declined to participate

Further details:

Preoperatively: education

Postoperatively: pain relief, early mobilisation and early oral feeding according to a specific schedule

Group 2: standard care $(\mathrm{n}=80)$

The outcomes reported were short-term mortality, serious adverse events, health-related quality of life, mild adverse events and length of hospital stay

Notes

Risk of bias

\begin{tabular}{|c|c|c|}
\hline Bias & Authors' judgement & Support for judgement \\
\hline $\begin{array}{l}\text { Random sequence generation (selection } \\
\text { bias) }\end{array}$ & Low risk & $\begin{array}{l}\text { Quote: "The patients were assigned either to the FTS } \\
\text { group or to the CS group by computer-generated random } \\
\text { numbers" }\end{array}$ \\
\hline Allocation concealment (selection bias) & Unclear risk & Comment: This information was not available \\
\hline $\begin{array}{l}\text { Blinding of participants and personnel } \\
\text { (performance bias) } \\
\text { All outcomes }\end{array}$ & Unclear risk & Comment: This information was not available \\
\hline
\end{tabular}

Blinding of outcome assessment (detection Unclear risk

Comment: This information was not available bias)

All outcomes 
Incomplete outcome data (attrition bias) Low risk All outcomes

\begin{tabular}{|c|c|c|}
\hline Selective reporting (reporting bias) & Low risk & Comment: All important outcomes were reported \\
\hline Other bias & Low risk & $\begin{array}{l}\text { Quote: "This study is supported by the StateKey In- } \\
\text { fectious Disease Project of China ( } 2012 \text { ZX10002010, } \\
2012 Z X 10002016) \text {, Science Fund for Creative Research } \\
\text { Groups, NSFC, China 81221061, Nursing Research } \\
\text { Fund of EHBH (12HL001)" }\end{array}$ \\
\hline
\end{tabular}

Wang 2010

\begin{tabular}{l|l}
\hline Methods & Randomised controlled trial \\
\hline Participants & Country: China \\
& Number randomised: 94 \\
& Post-randomisation drop-outs: $2(2.1 \%)$ \\
& Revised sample size: 92 \\
& Average age: 58 years \\
Females: $31(33.7 \%)$ & Inclusion criteria \\
& 1. Clinical diagnosis of gastric cancer \\
2. Patients younger than 80 \\
3. No preoperative chemoradiotherapy \\
Exclusion criteria \\
1. Primary diabetes mellitus \\
2. Impaired glucose tolerance \\
3. Primary hepatonephric diseases \\
4. Primary cardio-cerebral diseases \\
5. Severe obesity or BMI $>30 \mathrm{Kg} / \mathrm{m}^{2}$ \\
6. Severe malnutrition BMI $<15 \mathrm{Kg} / \mathrm{m}^{2}$ \\
7. Hyperthyroidism \\
8. Hypothyroidism \\
\hline
\end{tabular}

Interventions

Participants were randomly assigned to two groups

Group 1: enhanced recovery protocol $(n=45)$

Further details:

Preoperatively: education

Postoperatively: pain relief, early mobilisation and early oral feeding according to a specific schedule

Group 2: standard care $(\mathrm{n}=47)$

Outcomes

The outcomes reported were short-term mortality, mild adverse events, length of hospital stay, readmissions and costs

Notes 
Wang 2010 (Continued)

\section{Risk of bias}

\begin{tabular}{|c|c|c|}
\hline Bias & Authors' judgement & Support for judgement \\
\hline $\begin{array}{l}\text { Random sequence generation (selection } \\
\text { bias) }\end{array}$ & Unclear risk & Comment: This information was not available \\
\hline Allocation concealment (selection bias) & Unclear risk & Comment: This information was not available \\
\hline $\begin{array}{l}\text { Blinding of participants and personnel } \\
\text { (performance bias) } \\
\text { All outcomes }\end{array}$ & Unclear risk & Comment: This information was not available \\
\hline $\begin{array}{l}\text { Blinding of outcome assessment (detection } \\
\text { bias) } \\
\text { All outcomes }\end{array}$ & Unclear risk & Comment: This information was not available \\
\hline $\begin{array}{l}\text { Incomplete outcome data (attrition bias) } \\
\text { All outcomes }\end{array}$ & High risk & $\begin{array}{l}\text { Quote: "Two patients who withdrew their consent in the } \\
\text { FTS group were excluded from the study" } \\
\text { Comment: The reason for withdrawal was not reported }\end{array}$ \\
\hline Selective reporting (reporting bias) & High risk & Comment: Complications were not reported adequately \\
\hline Other bias & Unclear risk & $\begin{array}{l}\text { Comment: Information on source of funding was not } \\
\text { available }\end{array}$ \\
\hline
\end{tabular}

Zhao 2014

Methods

Participants
Randomised controlled trial

Country: China

Number randomised: 80

Post-randomisation drop-outs: 12 (15\%)

Revised sample size: 68

Average age: 57 years

Females: 16 (23.5\%)

Inclusion criteria

Patients with oesophageal cancer undergoing oesophagectomy

Exclusion criteria

1. A tumour of the hypopharynx

2. Tumour of the cervical oesophagus

3. Serious comorbidity

4. ASA 3 and 4

5. Preoperative distant metastasis

6. Perioperative instability.

7. Moderate risk factors e.g. previous coronary artery bypass graft, mild chronic obstructive pulmonary disease, Karnofsky index less than 60 , BMI less than $18.5 \mathrm{~kg} / \mathrm{m}^{2}$

8. Age of 65 to 75 with hypertension, diabetes or vascular disease 
Zhao 2014 (Continued)

\begin{tabular}{|c|c|c|}
\hline Interventions & \multicolumn{2}{|c|}{$\begin{array}{l}\text { Participants were randomly assigned to two groups } \\
\text { Group 1: enhanced recovery protocol }(\mathrm{n}=34) \\
\text { Further details: } \\
\text { Preoperatively: education } \\
\text { Postoperatively: pain relief according to a specific schedule } \\
\text { Group 2: standard care }(\mathrm{n}=34)\end{array}$} \\
\hline Outcomes & \multicolumn{2}{|c|}{$\begin{array}{l}\text { The outcomes reported were serious adverse events, mild adverse events, length of hospital } \\
\text { stay, readmissions and costs }\end{array}$} \\
\hline Notes & \multicolumn{2}{|c|}{ Reasons for post-randomisation drop-outs: Protocol violation } \\
\hline \multicolumn{3}{|l|}{ Risk of bias } \\
\hline Bias & Authors' judgement & Support for judgement \\
\hline $\begin{array}{l}\text { Random sequence generation (selection } \\
\text { bias) }\end{array}$ & Low risk & $\begin{array}{l}\text { Quote: "Enrolled patients were randomly assigned to two } \\
\text { groups using computer-generated random numbers (ran- } \\
\text { dom digits from } 0 \text { to 99)" }\end{array}$ \\
\hline Allocation concealment (selection bias) & Low risk & $\begin{array}{l}\text { Quote: "The investigators who designed the study pre- } \\
\text { pared the envelopes and assigned participants to their } \\
\text { groups but had no contact with the patients throughout } \\
\text { the study. The investigator who recruited the patients, } \\
\text { administered the interventions, and evaluated the out- } \\
\text { comes was not involved in the randomization process" }\end{array}$ \\
\hline $\begin{array}{l}\text { Blinding of participants and personnel } \\
\text { (performance bias) } \\
\text { All outcomes }\end{array}$ & Unclear risk & Comment: This information was not available \\
\hline $\begin{array}{l}\text { Blinding of outcome assessment (detection } \\
\text { bias) } \\
\text { All outcomes }\end{array}$ & Unclear risk & Comment: This information was not available \\
\hline $\begin{array}{l}\text { Incomplete outcome data (attrition bias) } \\
\text { All outcomes }\end{array}$ & High risk & Comment: There were post-randomisation drop-outs \\
\hline Selective reporting (reporting bias) & High risk & Comment: Complications were not reported adequately \\
\hline Other bias & Low risk & $\begin{array}{l}\text { Quote: Science Foundation of Heilongjiang health dept, } \\
\text { the science foundation of Heilongjiang Education dept } \\
\text { and the China postdoctoral Science foundation }\end{array}$ \\
\hline
\end{tabular}

BMI: body mass index; CS: conventional surgery; FTS: fast track surgery; LAPD: local anaesthesia pump device; LSG: laparoscopic sleeve gastrectomy.

Enhanced recovery protocols for major upper gastrointestinal, liver and pancreatic surgery (Review) 
Characteristics of excluded studies [ordered by study ID]

\begin{tabular}{|c|c|}
\hline Study & Reason for exclusion \\
\hline Cheifetz 2010 & Not specific to major upper gastrointestinal, liver or pancreatic surgery \\
\hline Dejong 2014 & Not a randomised controlled trial \\
\hline Feldman 2014 & Not a randomised controlled trial \\
\hline Gillissen 2011 & Comparison between two enhanced recovery protocols \\
\hline Hendry 2010 & Not a randomised controlled trial \\
\hline Hubner 2012 & Not specific to major upper gastrointestinal, liver or pancreatic surgery \\
\hline Revie 2012 & Not a randomised controlled trial \\
\hline Sahoo 2014 & Not a randomised controlled trial \\
\hline Serclova 2009 & Not major upper gastrointestinal, liver or pancreatic surgery \\
\hline Strobel 2013 & Comment on an included study (Jones 2013) \\
\hline Wattchow 2009 & Not major upper gastrointestinal, liver or pancreatic surgery \\
\hline
\end{tabular}

\section{Characteristics of studies awaiting assessment [ordered by study ID]}

Geubbels 2014

\begin{tabular}{ll}
\hline Methods & Randomised controlled trial \\
\hline Participants & Patients undergoing laparoscopic Roux-en-Y gastric bypass surgery \\
\hline Interventions & Fast-track surgery \\
\hline Outcomes & Complication rate (no raw data) \\
\hline Notes & Unclear if enhanced recovery protocol, as per definition used in the review, was used \\
\hline
\end{tabular}


Jin 2013

\begin{tabular}{ll}
\hline Methods & Randomised controlled trial \\
\hline Participants & Patients undergoing pancreaticoduodenectomy \\
\hline Interventions & Fast-track surgery \\
\hline Outcomes & Complication rate, length of hospital stay (no raw data) \\
\hline Notes & Unclear if enhanced recovery protocol, as per definition used in the review, was used \\
\hline NCT02348229 & \\
\hline Methods & Randomised controlled trial \\
\hline Participants & Patients undergoing laparoscopic assisted gastrectomy \\
\hline Interventions & Enhanced recovery protocol \\
\hline Outcomes & Length of hospital stay (no results reported) \\
\hline Notes & Unclear if enhanced recovery protocol, as per definition used in the review, was used \\
\hline
\end{tabular}

\section{Wang 2014}

\begin{tabular}{ll}
\hline Methods & Randomised controlled trial \\
\hline Participants & Patients undergoing gastrectomy \\
\hline Interventions & Fast-track surgery \\
\hline Outcomes & Complication rate, length of hospital stay and costs (number of people allocated to each group was not reported) \\
\hline Notes & Unclear if enhanced recovery protocol, as per definition used in the review, was used \\
\hline
\end{tabular}

\section{Characteristics of ongoing studies [ordered by study ID]}

\section{JPRN-UMIN000011572}

\begin{tabular}{ll}
\hline Trial name or title & JPRN-UMIN000011572 \\
\hline Methods & Randomised controlled trial \\
\hline Participants & Patients requiring pancreaticoduodenectomy \\
\hline Interventions & Enhanced recovery after protocol
\end{tabular}


JPRN-UMIN000011572 (Continued)

\begin{tabular}{ll}
\hline Outcomes & Length of postoperative hospital stay, postoperative morbidity and mortality, medical cost and safety \\
\hline Starting date & May 2014 \\
\hline Contact information & Ryuichi Yoshida (ryuichi-yoshida@md.okayama-u.ac.jp) \\
\hline Notes & \\
\hline
\end{tabular}

JPRN-UMIN000014068

\begin{tabular}{|c|c|}
\hline Trial name or title & JPRN-UMIN000014068 \\
\hline Methods & Randomised controlled trial \\
\hline Participants & Patients requiring gastrectomy \\
\hline Interventions & Enhanced recovery after protocol \\
\hline Outcomes & Length of postoperative hospital stay, postoperative morbidity and mortality \\
\hline Starting date & September 2013 \\
\hline Contact information & Kazuhisa Uchiyama (uchi@poh.osaka-med.ac.jp) \\
\hline \multicolumn{2}{|l|}{ Notes } \\
\hline \multicolumn{2}{|l|}{ NCT01766765 } \\
\hline Trial name or title & NCT01766765 \\
\hline Methods & Randomised controlled trial \\
\hline Participants & Patients requiring laparoscopic gastrectomy \\
\hline Interventions & Enhanced recovery after protocol \\
\hline Outcomes & Length of postoperative hospital stay and mortality \\
\hline Starting date & April 2013 \\
\hline Contact information & Qi Mao (maoqimdphd@gmail.com) \\
\hline Notes & \\
\hline
\end{tabular}


NCT01938313

\begin{tabular}{ll}
\hline Trial name or title & NCT01938313 \\
\hline Methods & Randomised controlled trial \\
\hline Participants & Patients requiring laparoscopic gastrectomy \\
\hline Interventions & Enhanced recovery after protocol \\
\hline Outcomes & Length of postoperative hospital stay, postoperative complications and quality of life \\
\hline Starting date & August 2012 \\
\hline Contact information & Hyung-Ho Kim (hhkim@snubh.org) \\
\hline Notes & \\
\hline
\end{tabular}


DATA AND ANALYSES

Comparison 1. Enhanced recovery protocol versus standard care

\begin{tabular}{lccll} 
Outcome or subgroup title & $\begin{array}{c}\text { No. of } \\
\text { studies }\end{array}$ & $\begin{array}{c}\text { No. of } \\
\text { participants }\end{array}$ & \multicolumn{1}{c}{ Statistical method } & Effect size \\
\hline 1 Short-term mortality & 7 & 868 & Risk Ratio (M-H, Fixed, 95\% CI) & $2.79[0.44,17.73]$ \\
$\begin{array}{l}\text { 2 Serious adverse events } \\
\quad \text { proportion) }\end{array}$ & 2 & 341 & Risk Ratio (M-H, Fixed, 95\% CI) & $5.57[0.68,45.89]$ \\
3 Serious adverse events (number) & 7 & 859 & Rate Ratio (Fixed, 95\% CI) & $0.72[0.45,1.13]$ \\
4 Health-related quality of life & 4 & 373 & Std. Mean Difference (IV, Random, 95\% CI) & $0.29[-0.04,0.62]$ \\
5 Mild adverse events (proportion) & 4 & 525 & Risk Ratio (M-H, Fixed, 95\% CI) & $0.58[0.39,0.85]$ \\
6 Mild adverse events (number) & 9 & 1014 & Rate Ratio (Fixed, 95\% CI) & $0.52[0.39,0.70]$ \\
7 Length of hospital stay & 9 & 1014 & Mean Difference (IV, Fixed, 95\% CI) & $-2.19[-2.53,-1.85]$ \\
8 Readmissions & 7 & 733 & Risk Ratio (M-H, Fixed, 95\% CI) & $1.40[0.69,2.87]$ \\
9 Costs & 4 & 282 & Mean Difference (IV, Fixed, 95\% CI) & $-0.63[-0.84,-0.42]$ \\
\hline
\end{tabular}

Comparison 2. Enhanced recovery protocol versus standard care (subgroup analysis)

\begin{tabular}{lcclll} 
Outcome or subgroup title & $\begin{array}{c}\text { No. of } \\
\text { studies }\end{array}$ & $\begin{array}{c}\text { No. of } \\
\text { participants }\end{array}$ & \multicolumn{1}{c}{ Statistical method } & Effect size \\
\hline 1 Short-term mortality & 6 & 747 & Risk Ratio (M-H, Fixed, 95\% CI) & $0.98[0.06,15.17]$ \\
1.1 Oesophagectomy & 0 & 0 & Risk Ratio (M-H, Fixed, 95\% CI) & $0.0[0.0,0.0]$ \\
1.2 Gastrectomy & 3 & 548 & Risk Ratio (M-H, Fixed, 95\% CI) & $0.98[0.06,15.17]$ \\
1.3 Liver surgery & 3 & 199 & Risk Ratio (M-H, Fixed, 95\% CI) & $0.0[0.0,0.0]$ \\
2 Serious adverse events & 2 & 341 & Risk Ratio (M-H, Fixed, 95\% CI) & $5.57[0.68,45.89]$ \\
$\quad$ (proportion) & & & & \\
2.1 Oesophagectomy & 0 & 0 & Risk Ratio (M-H, Fixed, 95\% CI) & $0.0[0.0,0.0]$ \\
2.2 Gastrectomy & 1 & 44 & Risk Ratio (M-H, Fixed, 95\% CI) & $3.0[0.13,69.87]$ \\
2.3 Liver surgery & 1 & 297 & Risk Ratio (M-H, Fixed, 95\% CI) & $8.39[0.44,161.01]$ \\
3 Serious adverse events (number) & 6 & & Rate Ratio (Fixed, 95\% CI) & $0.87[0.53,1.43]$ \\
3.1 Oesophagectomy & 1 & & Rate Ratio (Fixed, 95\% CI) & $0.33[0.01,8.12]$ \\
3.2 Gastrectomy & 2 & & Rate Ratio (Fixed, 95\% CI) & $1.10[0.35,3.49]$ \\
3.3 Liver surgery & 3 & & Rate Ratio (Fixed, 95\% CI) & $0.84[0.48,1.48]$ \\
4 Health-related quality of life & 4 & 373 & Std. Mean Difference (IV, Random, 95\% CI) & $0.29[-0.04,0.62]$ \\
$\quad$ 4.1 Oesophagectomy & 0 & 0 & Std. Mean Difference (IV, Random, 95\% CI) & $0.0[0.0,0.0]$ \\
4.2 Gastrectomy & 2 & 122 & Std. Mean Difference (IV, Random, 95\% CI) & $-0.03[-0.39,0.32]$ \\
4.3 Liver surgery & 2 & 251 & Std. Mean Difference (IV, Random, 95\% CI) & $0.52[0.27,0.77]$ \\
\hline
\end{tabular}

Enhanced recovery protocols for major upper gastrointestinal, liver and pancreatic surgery (Review) 
Comparison 3. Enhanced recovery protocol versus standard care (sensitivity analysis)

\begin{tabular}{lccll} 
Outcome or subgroup title & $\begin{array}{c}\text { No. of } \\
\text { studies }\end{array}$ & $\begin{array}{c}\text { No. of } \\
\text { participants }\end{array}$ & \multicolumn{1}{c}{ Statistical method } & Effect size \\
\hline 1 Health-related quality of life & 3 & 282 & Std. Mean Difference (IV, Random, 95\% CI) & $0.17[-0.19,0.53]$ \\
2 Length of hospital stay & 3 & 267 & Mean Difference (IV, Fixed, 95\% CI) & $-2.31[-2.93,-1.69]$ \\
3 Costs & 3 & 214 & Mean Difference (IV, Fixed, 95\% CI) & $-0.60[-0.81,-0.39]$ \\
\hline
\end{tabular}

Analysis I.I. Comparison I Enhanced recovery protocol versus standard care, Outcome I Short-term mortality.

\begin{tabular}{|c|c|c|c|c|c|}
\hline \multicolumn{6}{|c|}{ Comparison: I Enhanced recovery protocol versus standard care } \\
\hline \multicolumn{6}{|c|}{ Outcome: | Short-term mortality } \\
\hline \multirow[t]{2}{*}{ Study or subgroup } & $\begin{array}{r}\text { Enh. } \\
\text { recovery } \\
\text { protocol }\end{array}$ & Standard care & Risk Ratio & \multirow[t]{2}{*}{ Weight } & \multirow{2}{*}{$\begin{array}{r}\text { Risk Ratio } \\
\text { M-H,Fixed,95\% Cl }\end{array}$} \\
\hline & $\mathrm{n} / \mathrm{N}$ & $\mathrm{n} / \mathrm{N}$ & M-H,Fixed,95\% Cl & & \\
\hline Barlow 2011 & $3 / 64$ & $0 / 57$ & $\longrightarrow$ & $34.3 \%$ & $6.25[0.33,118.38]$ \\
\hline Jones 2013 & $1 / 46$ & $1 / 45$ & 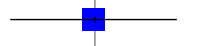 & $65.7 \%$ & $0.98[0.06,15.17]$ \\
\hline Kim 2012 & $0 / 22$ & $0 / 22$ & & & Not estimable \\
\hline Liu 2010 & $0 / 33$ & $0 / 30$ & & & Not estimable \\
\hline Lu 2014 & $0 / 135$ & $0 / 162$ & & & Not estimable \\
\hline $\mathrm{Ni} 2013$ & $0 / 80$ & $0 / 80$ & & & Not estimable \\
\hline Wang 2010 & $0 / 45$ & $0 / 47$ & & & Not estimable \\
\hline Total $(95 \% \mathrm{CI})$ & 425 & 443 & 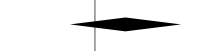 & $100.0 \%$ & $2.79[0.44,17.73]$ \\
\hline \multicolumn{6}{|c|}{ Total events: 4 (Enh. recovery protocol), I (Standard care) } \\
\hline \multicolumn{6}{|c|}{ Heterogeneity: $\mathrm{Ch}^{2}=0.85, \mathrm{df}=\mathrm{I}(\mathrm{P}=0.36) ; \mathrm{I}^{2}=0.0 \%$} \\
\hline \multicolumn{6}{|c|}{ Test for overall effect: $Z=1.09(P=0.28)$} \\
\hline Test for subgroup dif & ot applicable & & & & \\
\hline
\end{tabular}


Analysis I.2. Comparison I Enhanced recovery protocol versus standard care, Outcome 2 Serious adverse events (proportion).

Review: Enhanced recovery protocols for major upper gastrointestinal, liver and pancreatic surgery

Comparison: I Enhanced recovery protocol versus standard care

Outcome: 2 Serious adverse events (proportion)

\begin{tabular}{|c|c|c|c|c|c|}
\hline Study or subgroup & $\begin{array}{l}\text { Enh. } \\
\text { recovery } \\
\text { protocol }\end{array}$ & Standard care & Risk Ratio & Weight & Risk Ratio \\
\hline & $n / N$ & $\mathrm{n} / \mathrm{N}$ & M-H,Fixed,95\% Cl & & M-H,Fixed,95\% Cl \\
\hline Kim 2012 & $1 / 22$ & $0 / 22$ & $\begin{array}{l}\square \\
\end{array}$ & $52.4 \%$ & $3.00[0.13,69.87]$ \\
\hline Lu 2014 & $3 / 135$ & $0 / 162$ & $\rightarrow$ & $47.6 \%$ & $8.39[0.44,161.01]$ \\
\hline
\end{tabular}

Total (95\% CI)

157

184

Total events: 4 (Enh. recovery protocol), 0 (Standard care)

Heterogeneity: $\mathrm{Chi}^{2}=0.22, \mathrm{df}=\mathrm{I}(\mathrm{P}=0.64) ; \mathrm{I}^{2}=0.0 \%$

Test for overall effect: $Z=1.60(P=0.11)$

Test for subgroup differences: Not applicable 
Analysis I.3. Comparison I Enhanced recovery protocol versus standard care, Outcome 3 Serious adverse events (number).

Review: Enhanced recovery protocols for major upper gastrointestinal, liver and pancreatic surgery

Comparison: I Enhanced recovery protocol versus standard care

Outcome: 3 Serious adverse events (number)

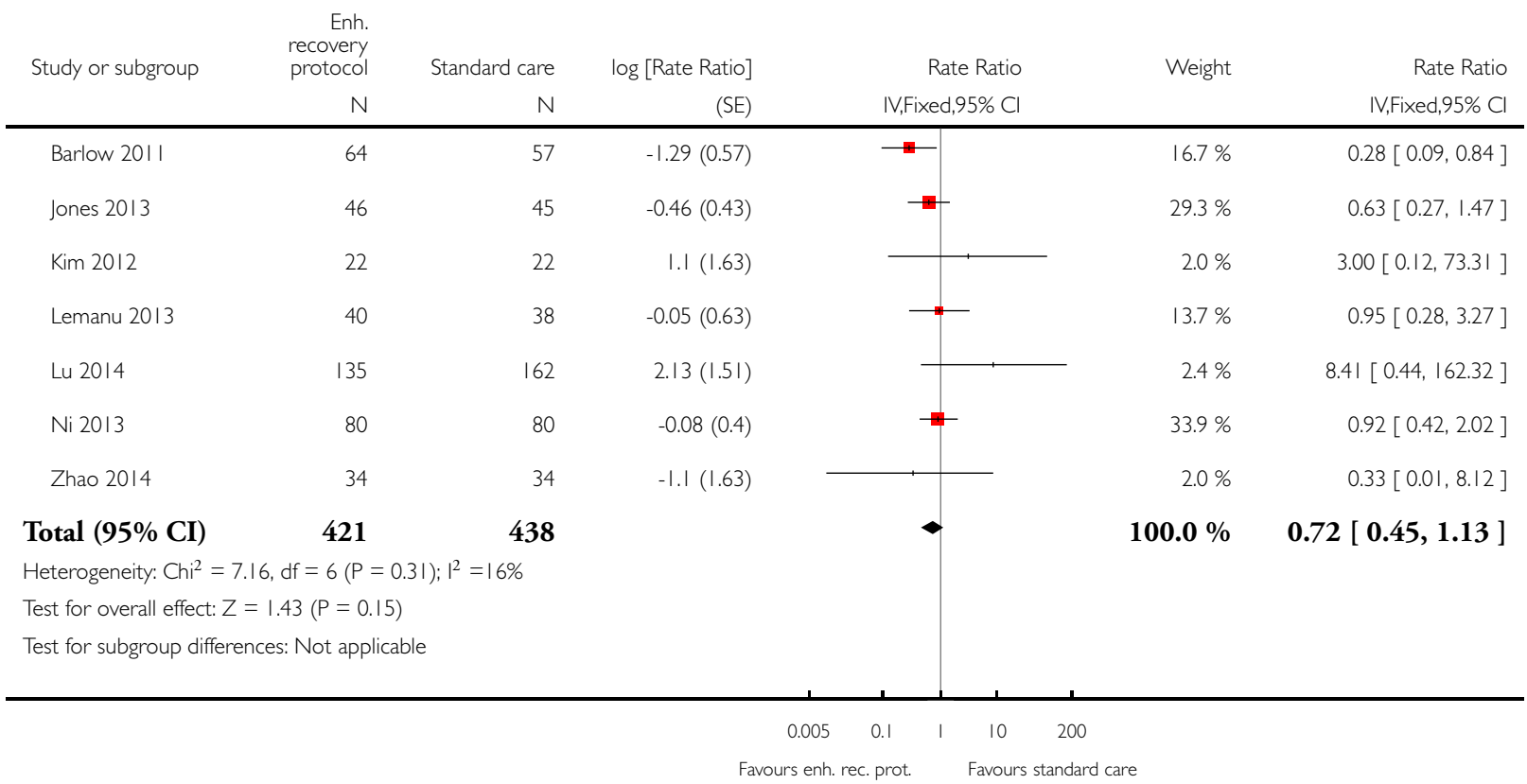


Analysis I.4. Comparison I Enhanced recovery protocol versus standard care, Outcome 4 Health-related quality of life.

Review: Enhanced recovery protocols for major upper gastrointestinal, liver and pancreatic surgery

Comparison: I Enhanced recovery protocol versus standard care

Outcome: 4 Health-related quality of life

\begin{tabular}{|c|c|c|c|c|c|c|c|}
\hline \multirow[t]{2}{*}{ Study or subgroup } & $\begin{array}{l}\text { Enh. } \\
\text { recovery } \\
\text { protocol }\end{array}$ & \multicolumn{3}{|c|}{ Standard care } & $\begin{array}{r}\text { Std. } \\
\text { Mean } \\
\text { Difference }\end{array}$ & \multirow[t]{2}{*}{ Weight } & $\begin{array}{r}\text { Std. } \\
\text { Mean } \\
\text { Difference }\end{array}$ \\
\hline & $N$ & Mean(SD) & $N$ & Mean(SD) & IV,Random,95\% Cl & & IV,Random,95\% Cl \\
\hline Jones 2013 & 46 & $37.2(2.4)$ & 45 & $35.6(2.4)$ & $\longrightarrow$ & $25.6 \%$ & $0.66[0.24,1.08]$ \\
\hline Kim 2012 & 22 & $8.9(2.46)$ & 22 & $9.28(2.4)$ & 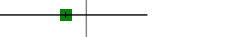 & $18.2 \%$ & $-0.15[-0.75,0.44]$ \\
\hline Lemanu 2013 & 40 & $80.5(10.2)$ & 38 & $80.1(10.1)$ & & $24.5 \%$ & $0.04[-0.41,0.48]$ \\
\hline Ni 2013 & 80 & $101.2(13)$ & 80 & $93.4(21.4)$ & 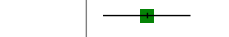 & $31.6 \%$ & $0.44[0.12,0.75]$ \\
\hline
\end{tabular}

Total (95\% CI)

188

185

$100.0 \% \quad 0.29[-0.04,0.62]$

Heterogeneity: Tau $^{2}=0.06 ; \mathrm{Chi}^{2}=7.03, \mathrm{df}=3(\mathrm{P}=0.07) ; \mathrm{I}^{2}=57 \%$

Test for overall effect: $Z=1.73(P=0.084)$

Test for subgroup differences: Not applicable

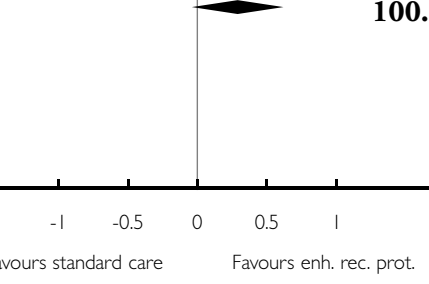


Analysis I.5. Comparison I Enhanced recovery protocol versus standard care, Outcome 5 Mild adverse events (proportion).

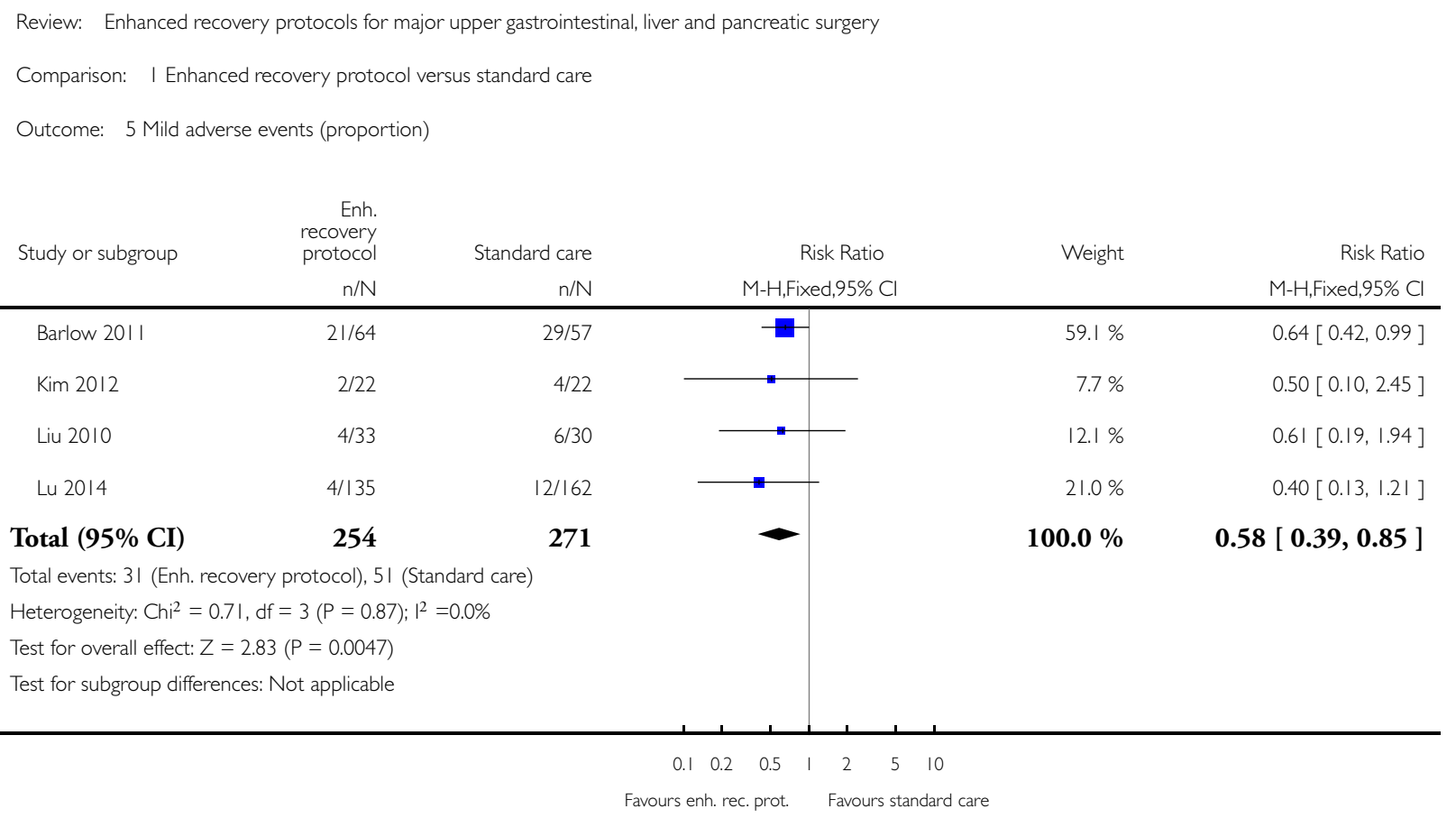




\section{Analysis I.6. Comparison I Enhanced recovery protocol versus standard care, Outcome 6 Mild adverse} events (number).

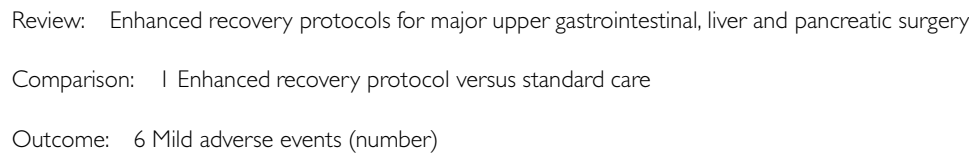

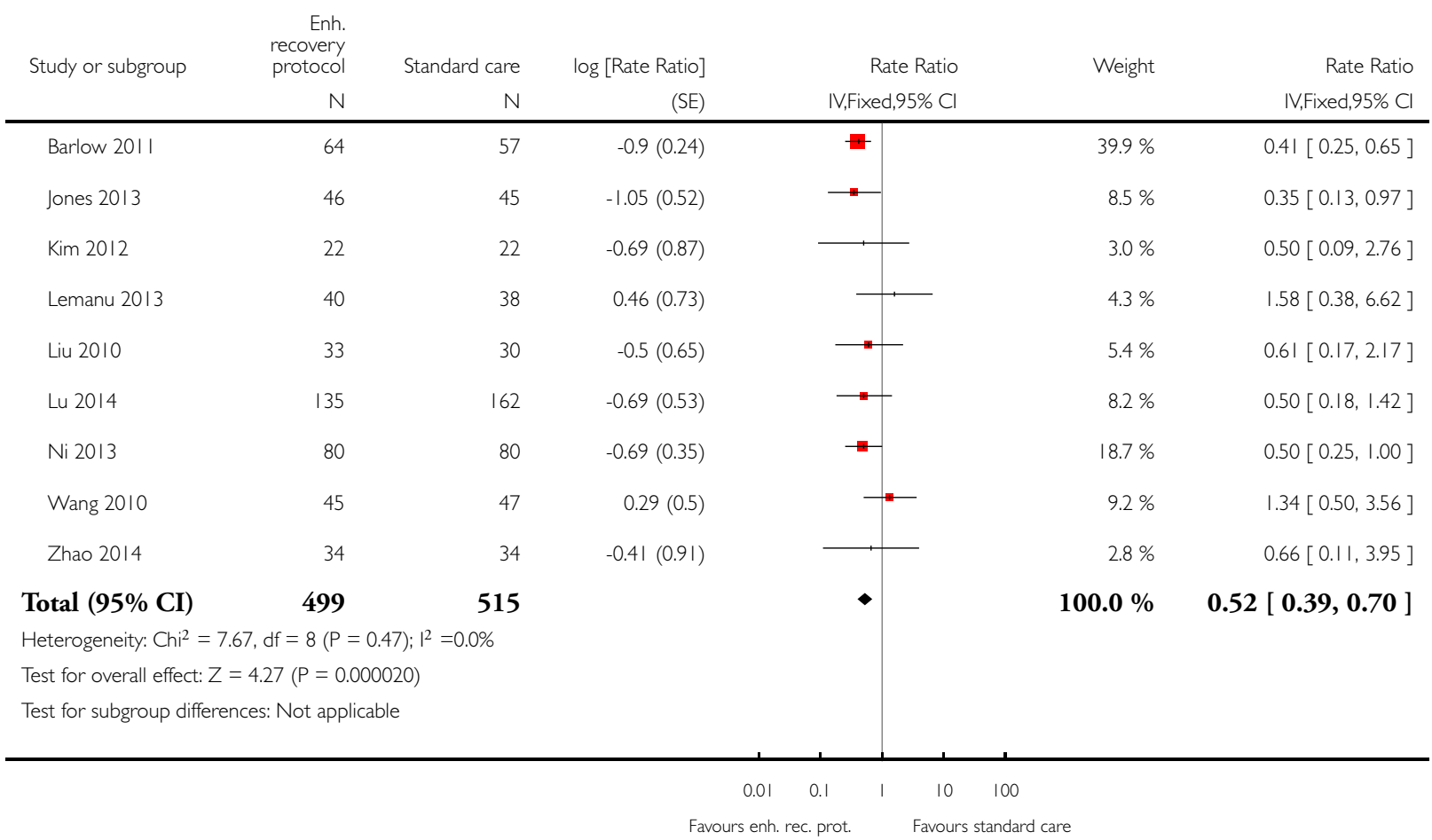


Analysis I.7. Comparison I Enhanced recovery protocol versus standard care, Outcome 7 Length of hospital stay.

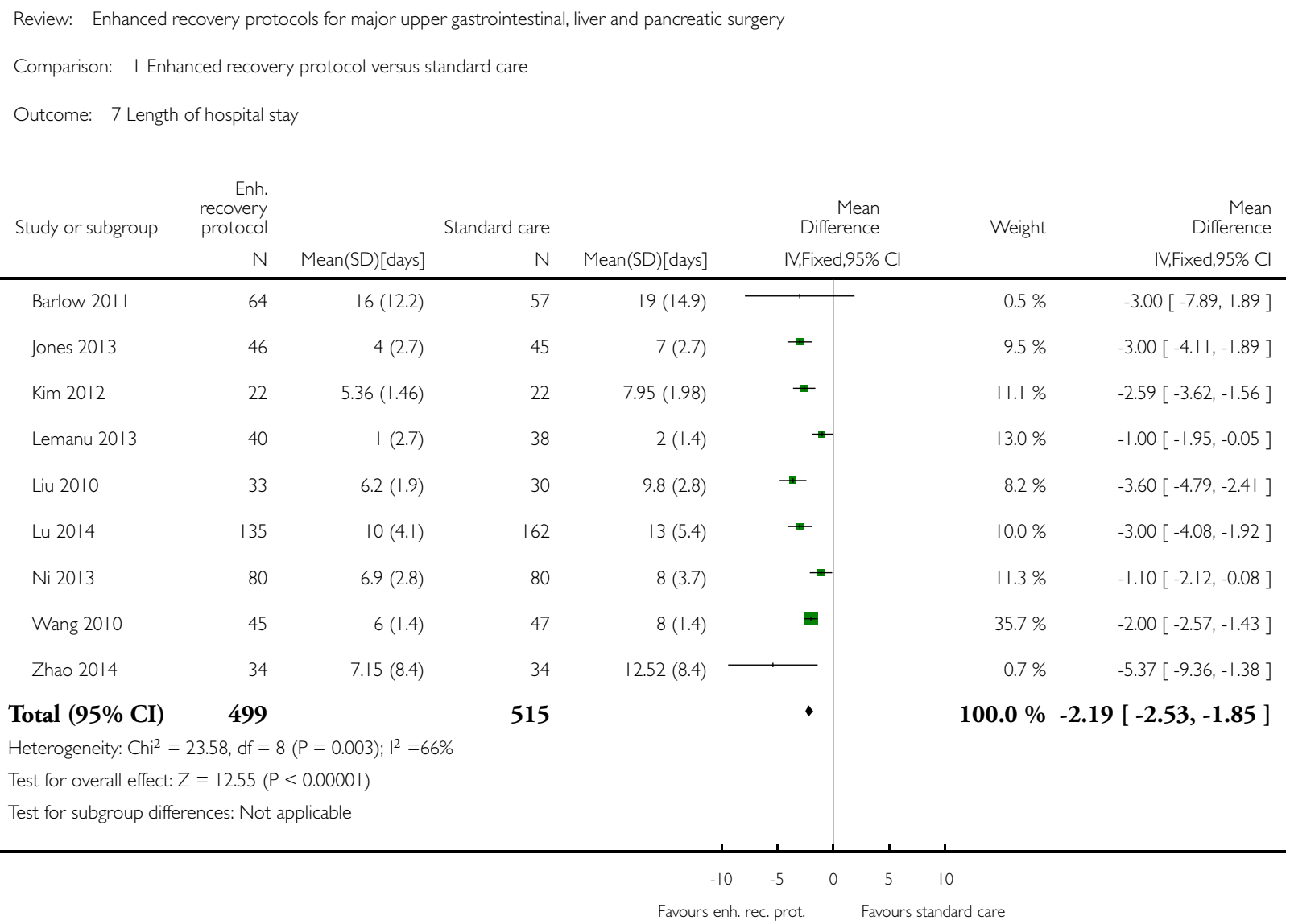


Analysis I.8. Comparison I Enhanced recovery protocol versus standard care, Outcome 8 Readmissions.

Review: Enhanced recovery protocols for major upper gastrointestinal, liver and pancreatic surgery

Comparison: I Enhanced recovery protocol versus standard care

Outcome: 8 Readmissions

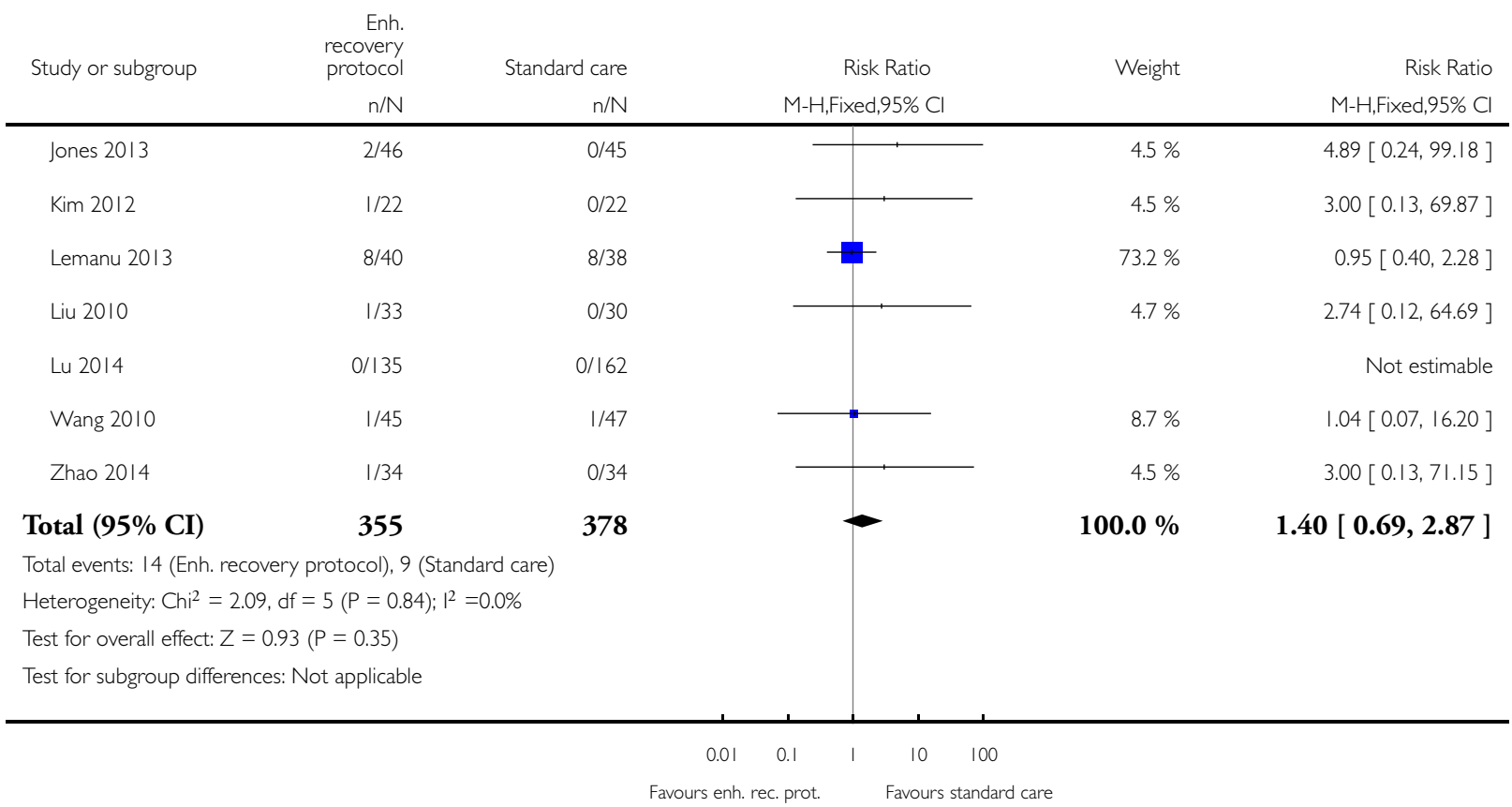




\section{Analysis I.9. Comparison I Enhanced recovery protocol versus standard care, Outcome 9 Costs.}

Review: Enhanced recovery protocols for major upper gastrointestinal, liver and pancreatic surgery

Comparison: I Enhanced recovery protocol versus standard care

Outcome: 9 Costs

\begin{tabular}{|c|c|c|c|c|c|c|c|}
\hline \multirow[t]{2}{*}{ Study or subgroup } & \multirow{2}{*}{$\begin{array}{r}\text { Enh. } \\
\text { recovery } \\
\text { protocol } \\
\mathrm{N}\end{array}$} & \multicolumn{2}{|c|}{ Standard care } & \multirow[b]{2}{*}{$\begin{array}{c}\text { Mean(SD)[,000 } \\
\text { USD] }\end{array}$} & $\begin{array}{r}\text { Mean } \\
\text { Difference }\end{array}$ & \multirow[t]{2}{*}{ Weight } & \multirow{2}{*}{$\begin{array}{r}\text { Mean } \\
\text { Difference } \\
\text { IV,Fixed, } 95 \% \mathrm{Cl}\end{array}$} \\
\hline & & $\begin{array}{c}\text { Mean(SD)[,000 } \\
\text { USD] }\end{array}$ & $\mathrm{N}$ & & IV,Fixed,95\% Cl & & \\
\hline Kim 2012 & \multicolumn{2}{|c|}{$227.4543(0.7058)$} & 22 & $7.77(0.9342)$ & $\mp$ & $18.2 \%$ & $-0.32[-0.81,0.17]$ \\
\hline Lemanu 2013 & 40 & I 1.127 (9.819) & 38 & $11.67(10.7 \mid 75) \longleftarrow$ & & $0.2 \%$ & $-0.55[-5.12,4.02]$ \\
\hline Wang 2010 & $4.354292(0.585437)$ & 45 & 47 & $5.02(0.582 \mid 65)$ & + & $76.5 \%$ & $-0.67[-0.91,-0.43]$ \\
\hline Zhao 2014 & $5.141196(1.956553)$ & 34 & 34 & $6.4(1.956553)$ & $\longrightarrow$ & $5.0 \%$ & $-1.26[-2.19,-0.33]$ \\
\hline Total $(95 \%$ CI $)$ & 141 & & 141 & & $\bullet$ & $100.0 \%$ & $3[-0.84,-0.42]$ \\
\hline \multicolumn{8}{|c|}{ Heterogeneity: $\mathrm{Chi}^{2}=3.4 \mathrm{I}, \mathrm{df}=3(\mathrm{P}=0.33) ; \mathrm{I}^{2}=12 \%$} \\
\hline \multicolumn{8}{|c|}{ Test for overall effect: $Z=5.94(P<0.0000 I)$} \\
\hline \multicolumn{8}{|c|}{ Test for subgroup differences: Not applicable } \\
\hline & & & & -4 & -2 & 4 & \\
\hline
\end{tabular}


Analysis 2.I. Comparison 2 Enhanced recovery protocol versus standard care (subgroup analysis), Outcome I Short-term mortality.

Review: Enhanced recovery protocols for major upper gastrointestinal, liver and pancreatic surgery

Comparison: 2 Enhanced recovery protocol versus standard care (subgroup analysis)

Outcome: I Short-term mortality

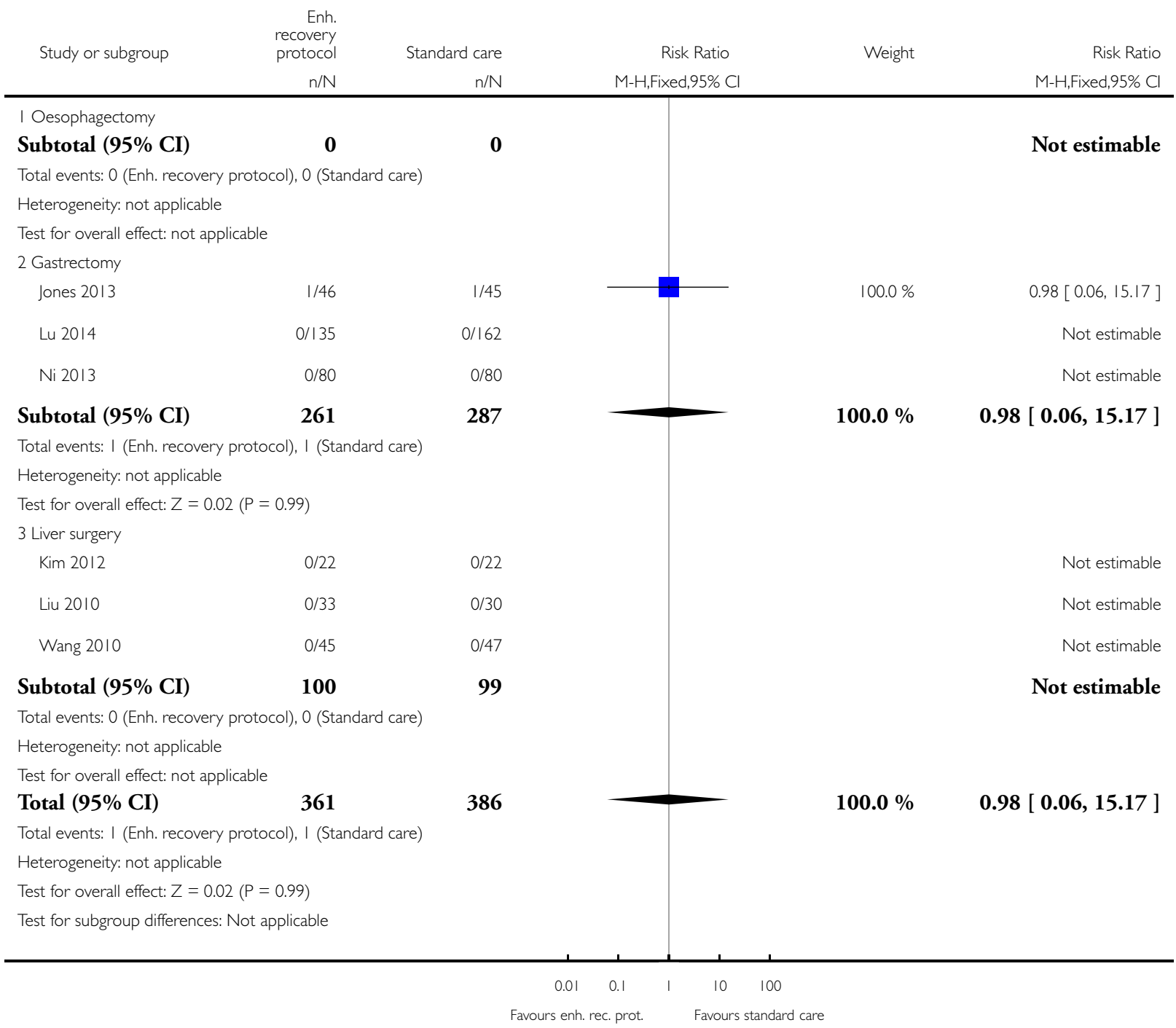




\section{Analysis 2.2. Comparison 2 Enhanced recovery protocol versus standard care (subgroup analysis),}

Outcome 2 Serious adverse events (proportion).

Review: Enhanced recovery protocols for major upper gastrointestinal, liver and pancreatic surgery

Comparison: 2 Enhanced recovery protocol versus standard care (subgroup analysis)

Outcome: 2 Serious adverse events (proportion)

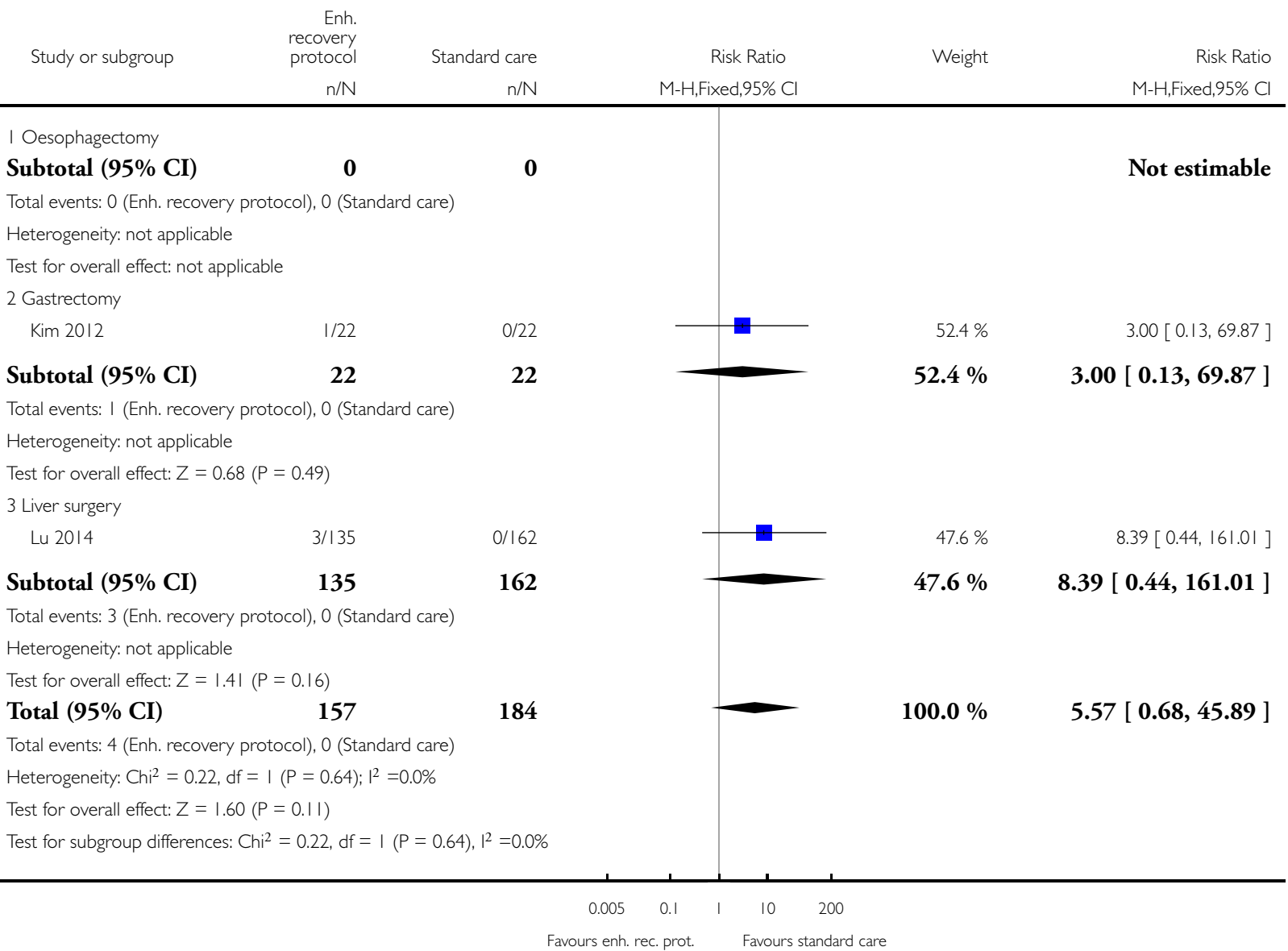


Analysis 2.3. Comparison 2 Enhanced recovery protocol versus standard care (subgroup analysis), Outcome 3 Serious adverse events (number).

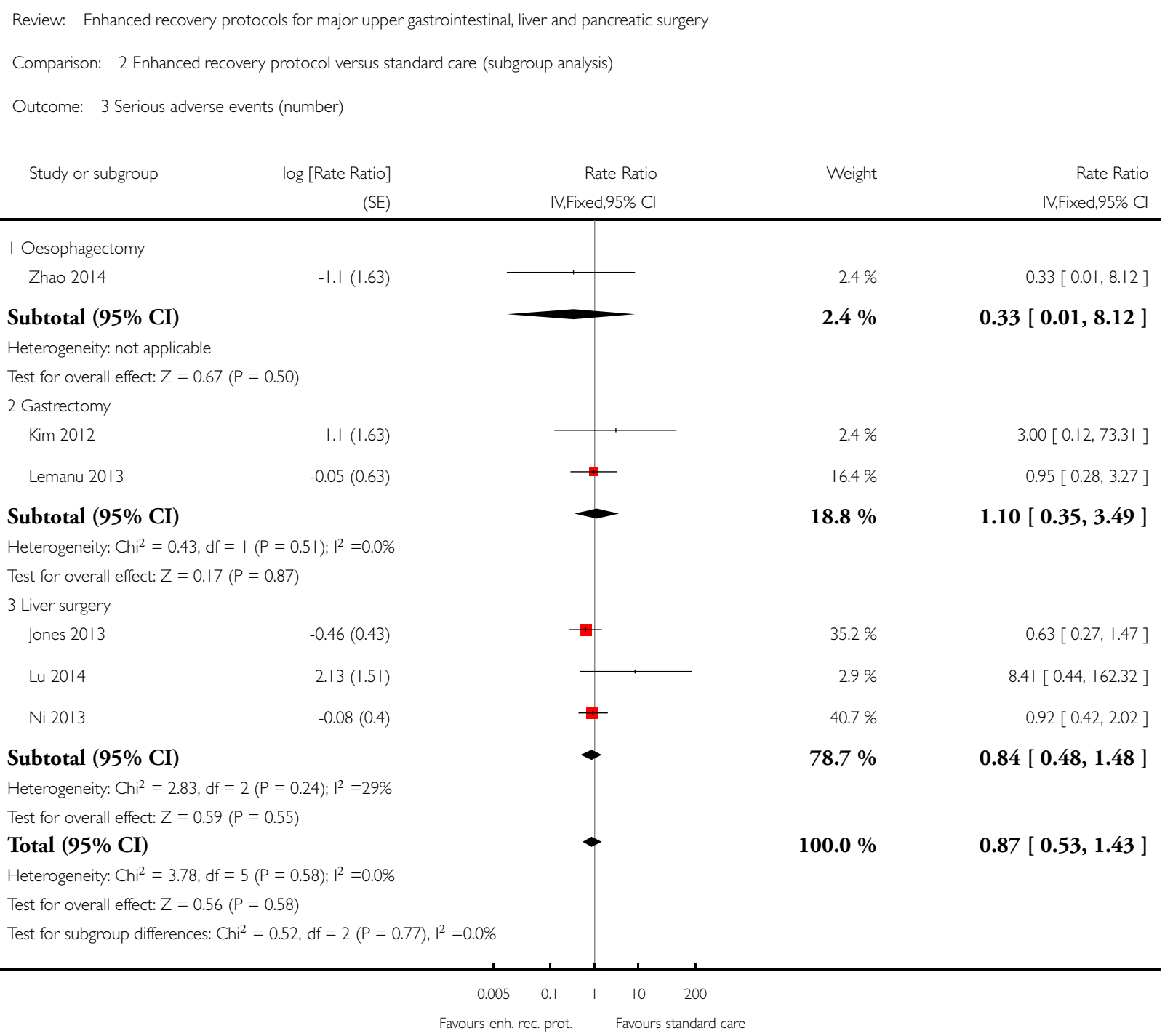


Analysis 2.4. Comparison 2 Enhanced recovery protocol versus standard care (subgroup analysis), Outcome 4 Health-related quality of life.

Review: Enhanced recovery protocols for major upper gastrointestinal, liver and pancreatic surgery

Comparison: 2 Enhanced recovery protocol versus standard care (subgroup analysis)

Outcome: 4 Health-related quality of life

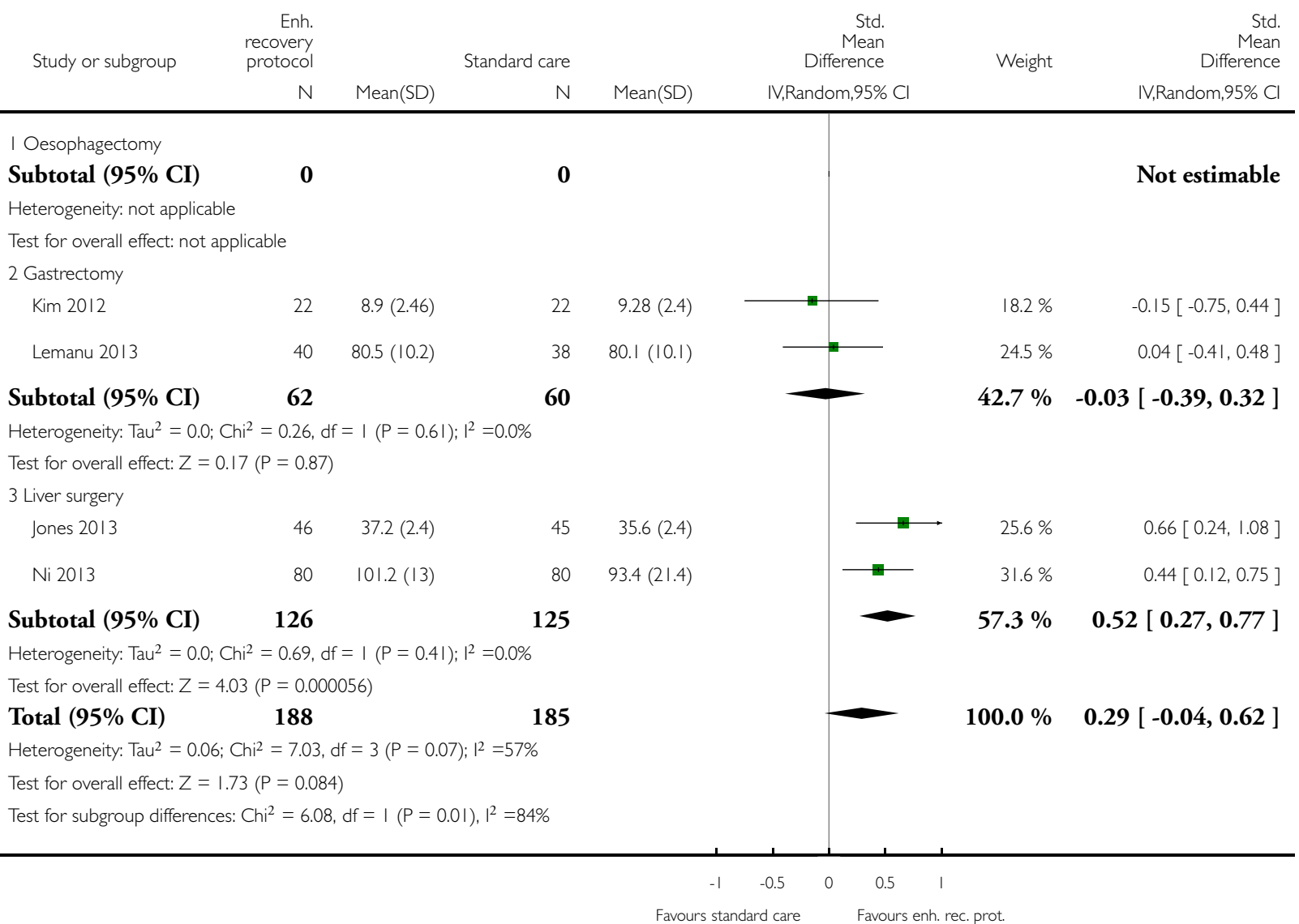


Analysis 3.I. Comparison 3 Enhanced recovery protocol versus standard care (sensitivity analysis), Outcome I Health-related quality of life.

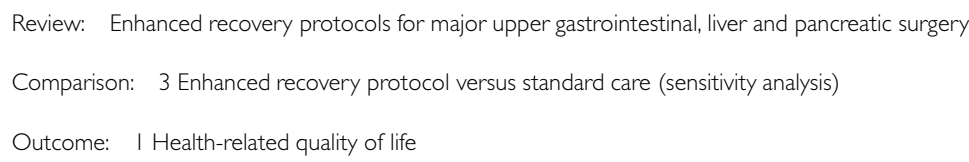

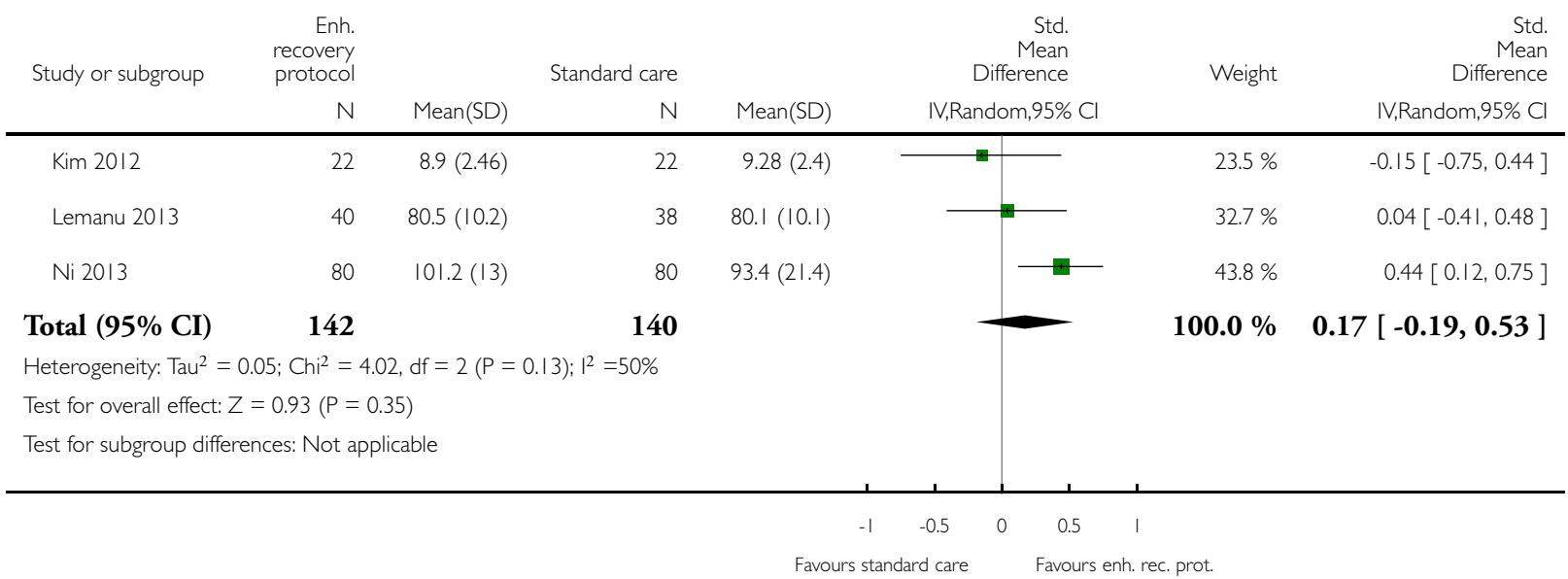


Analysis 3.2. Comparison 3 Enhanced recovery protocol versus standard care (sensitivity analysis), Outcome 2 Length of hospital stay.

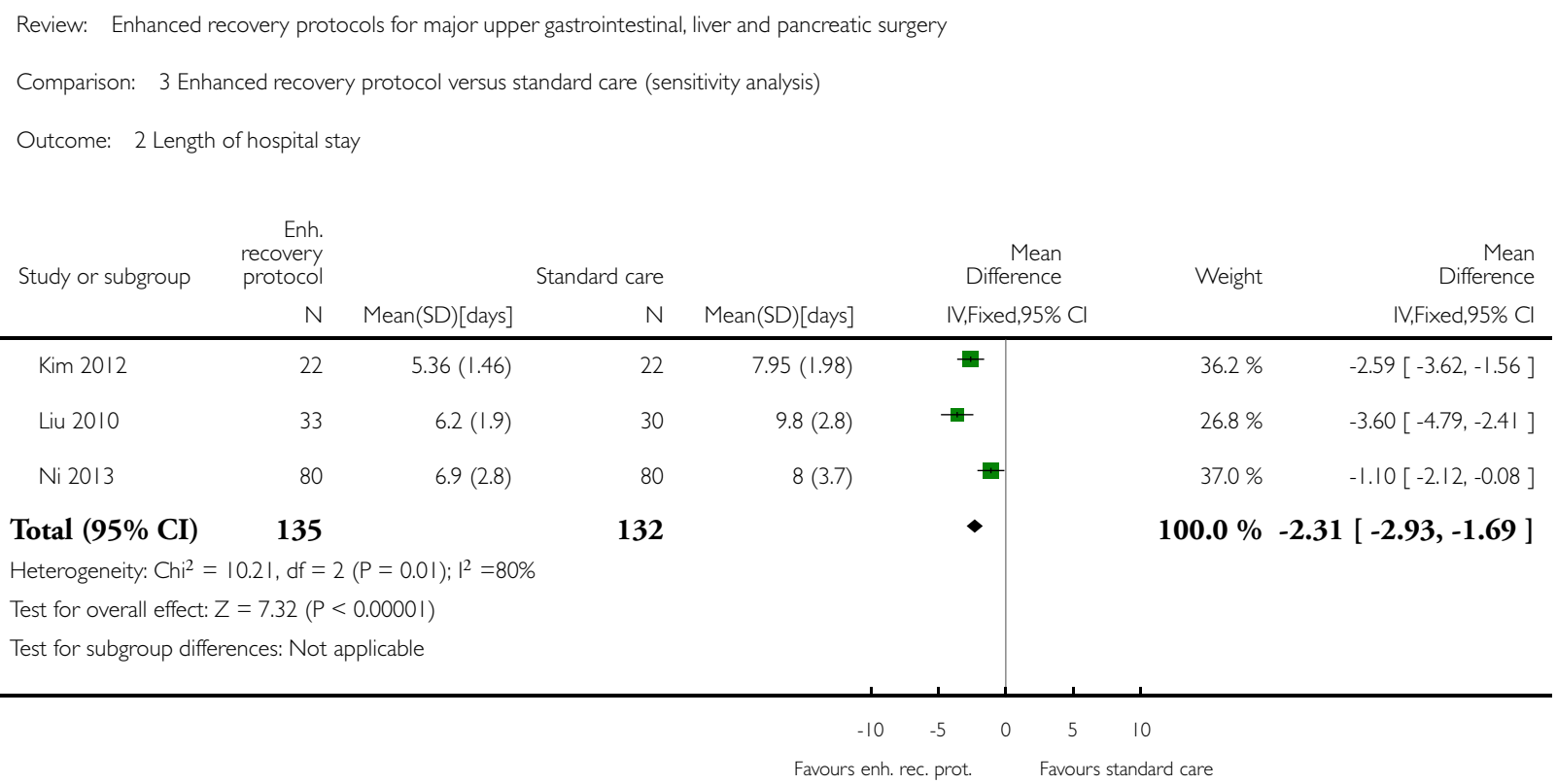


Analysis 3.3. Comparison 3 Enhanced recovery protocol versus standard care (sensitivity analysis), Outcome 3 Costs.

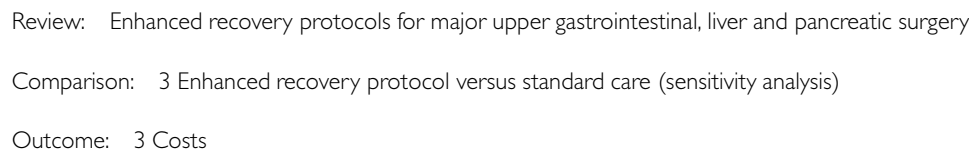

\begin{tabular}{|c|c|c|c|c|c|c|c|}
\hline \multirow[t]{2}{*}{ Study or subgroup } & \multirow{2}{*}{$\begin{array}{r}\text { Enh. } \\
\text { recovery } \\
\text { protocol } \\
\mathrm{N}\end{array}$} & \multicolumn{3}{|c|}{ Standard care } & \multirow{2}{*}{$\begin{array}{c}\text { Mean } \\
\text { Difference } \\
\text { IV,Fixed,95\% Cl }\end{array}$} & \multirow[t]{2}{*}{ Weight } & \multirow{2}{*}{$\begin{array}{r}\text { Mean } \\
\text { Difference } \\
\text { IV,Fixed,95\% Cl }\end{array}$} \\
\hline & & $\begin{array}{c}\text { Mean(SD)[,000 } \\
\text { USD }]\end{array}$ & $\mathrm{N}$ & $\begin{array}{c}\text { Mean(SD)[,000 } \\
\text { USD }]\end{array}$ & & & \\
\hline Kim 2012 & 22 & $7.4543(0.7058)$ & 22 & $7.77(0.9342)$ & $\mp$ & $19.2 \%$ & $-0.32[-0.81,0.17]$ \\
\hline Lemanu 2013 & 40 & $11.127(9.819)$ & 38 & 1 $1.67(10.7175)$ & & $0.2 \%$ & $-0.55[-5.12,4.02]$ \\
\hline Wang 2010 & $4.354292(0.585437)$ & 45 & 47 & $5.02(0.582165)$ & + & $80.6 \%$ & $-0.67[-0.91,-0.43]$ \\
\hline
\end{tabular}

Total (95\% CI) $107 \quad 107$

Heterogeneity: $\mathrm{Chi}^{2}=1.58, \mathrm{df}=2(\mathrm{P}=0.45) ; \mathrm{I}^{2}=0.0 \%$

Test for overall effect: $Z=5.48(P<0.0000$ I)

Test for subgroup differences: Not applicable

\section{ADDITIONAL TABLES}

Table 1. Participants, elements of enhanced recovery protocol and outcomes reported in included trials

\begin{tabular}{|c|c|c|c|c|c|c|c|}
\hline Study name & Surgery & $\begin{array}{l}\text { Preoperative } \\
\text { education }\end{array}$ & $\begin{array}{l}\text { Pain relief } \\
\text { protocol }\end{array}$ & $\begin{array}{l}\text { Early mobili- } \\
\text { sation proto- } \\
\text { col }\end{array}$ & $\begin{array}{l}\text { Nutritional } \\
\text { protocol }\end{array}$ & $\begin{array}{l}\text { Growth fac- } \\
\text { tors }\end{array}$ & $\begin{array}{l}\text { Outcomes re- } \\
\text { ported }\end{array}$ \\
\hline Barlow 2011 & $\begin{array}{l}\text { Major upper } \\
\text { gastrointesti- } \\
\text { nal surgery } \\
\text { (oesophagec- } \\
\text { tomy, gastrec- } \\
\text { tomy and pan- } \\
\text { createctomy) }\end{array}$ & No & No & No & Yes & No & $\begin{array}{l}\text { 1. Short- } \\
\text { term } \\
\text { mortality } \\
\text { 2. Serious } \\
\text { adverse events } \\
\text { 3. Mild } \\
\text { adverse events } \\
\text { 4. Length } \\
\text { of hospital } \\
\text { stay }\end{array}$ \\
\hline Jones 2013 & $\begin{array}{l}\text { Open liver } \\
\text { surgery }\end{array}$ & Yes & No & Yes & Yes & No & $\begin{array}{l}\text { 1. Short- } \\
\text { term } \\
\text { mortality }\end{array}$ \\
\hline
\end{tabular}


Table 1. Participants, elements of enhanced recovery protocol and outcomes reported in included trials

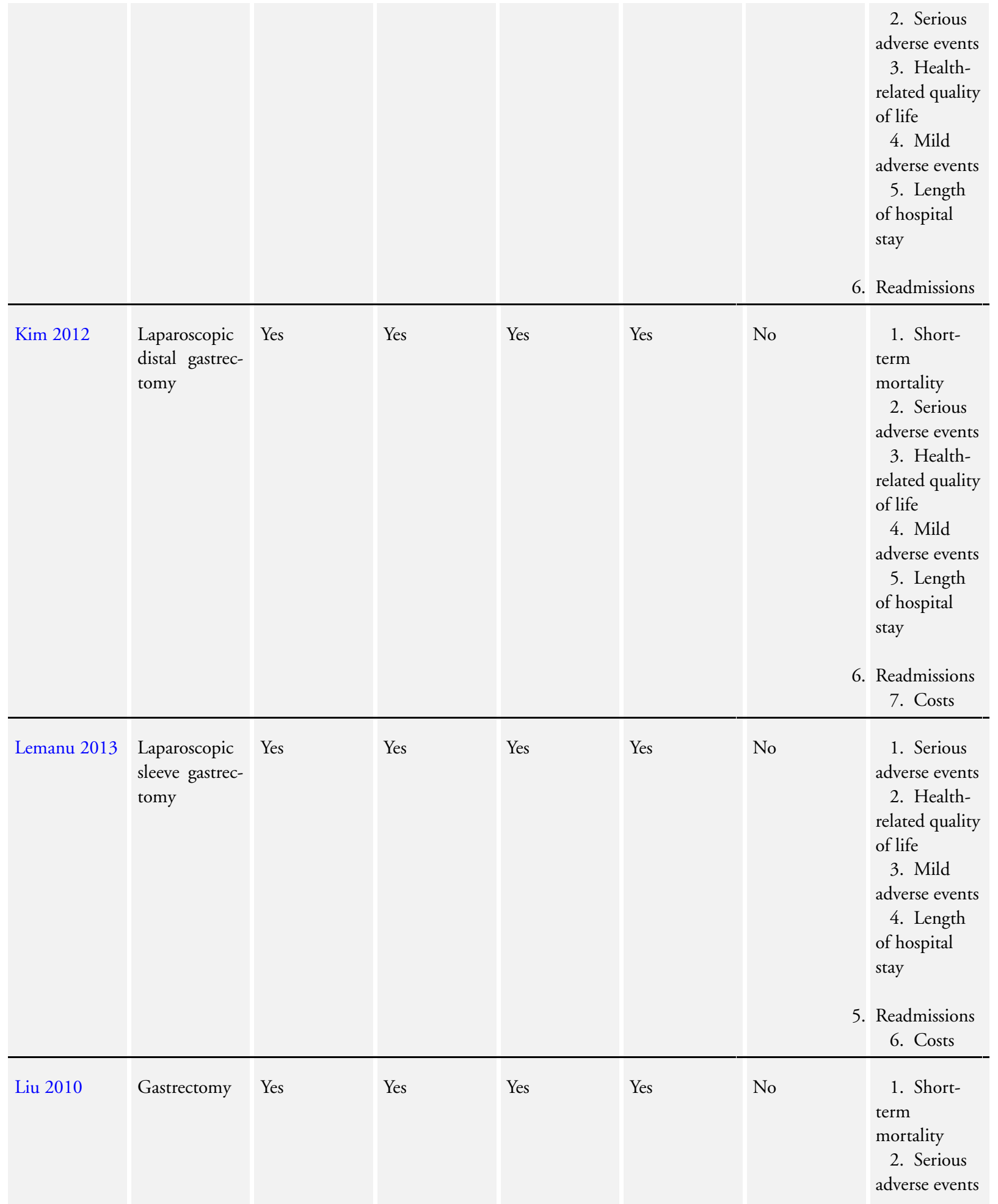


Table 1. Participants, elements of enhanced recovery protocol and outcomes reported in included trials

(Continued)

\begin{tabular}{|c|c|c|c|c|c|c|c|}
\hline & & & & & & 5. & $\begin{array}{l}\text { 3. Mild } \\
\text { adverse events } \\
\text { 4. Length } \\
\text { of hospital } \\
\text { stay } \\
\text { Readmissions }\end{array}$ \\
\hline Lu 2014 & Liver surgery & No & No & Yes & Yes & No & $\begin{array}{l}\text { 1. Short- } \\
\text { term } \\
\text { mortality } \\
\text { 2. Serious } \\
\text { adverse events } \\
\text { 3. Mild } \\
\text { adverse events } \\
\text { 4. Length } \\
\text { of hospital } \\
\text { stay }\end{array}$ \\
\hline
\end{tabular}

5. Readmissions

\begin{tabular}{|c|c|c|c|c|c|c|c|}
\hline Miyachi 2013 & Gastrectomy & No & No & No & No & Yes & $\begin{array}{l}\text { None of the } \\
\text { out- } \\
\text { comes of in- } \\
\text { terest were re- } \\
\text { ported }\end{array}$ \\
\hline Ni 2013 & $\begin{array}{l}\text { Partial liver re- } \\
\text { section }\end{array}$ & Yes & Yes & Yes & Yes & No & $\begin{array}{l}\text { 1. Short- } \\
\text { term } \\
\text { mortality } \\
\text { 2. Serious } \\
\text { adverse events } \\
\text { 3. Health- } \\
\text { related quality } \\
\text { of life } \\
\text { 4. Mild } \\
\text { adverse events } \\
\text { 5. Length } \\
\text { of hospital } \\
\text { stay }\end{array}$ \\
\hline Wang 2010 & Gastrectomy & Yes & Yes & Ys & Yes & No & $\begin{array}{l}\text { 1. Short- } \\
\text { term } \\
\text { mortality } \\
\text { 2. Mild } \\
\text { adverse events } \\
\text { 3. Length } \\
\text { of hospital } \\
\text { stay }\end{array}$ \\
\hline
\end{tabular}

Enhanced recovery protocols for major upper gastrointestinal, liver and pancreatic surgery (Review)

Copyright $\odot 2016$ The Cochrane Collaboration. Published by John Wiley \& Sons, Ltd. 
Table 1. Participants, elements of enhanced recovery protocol and outcomes reported in included trials

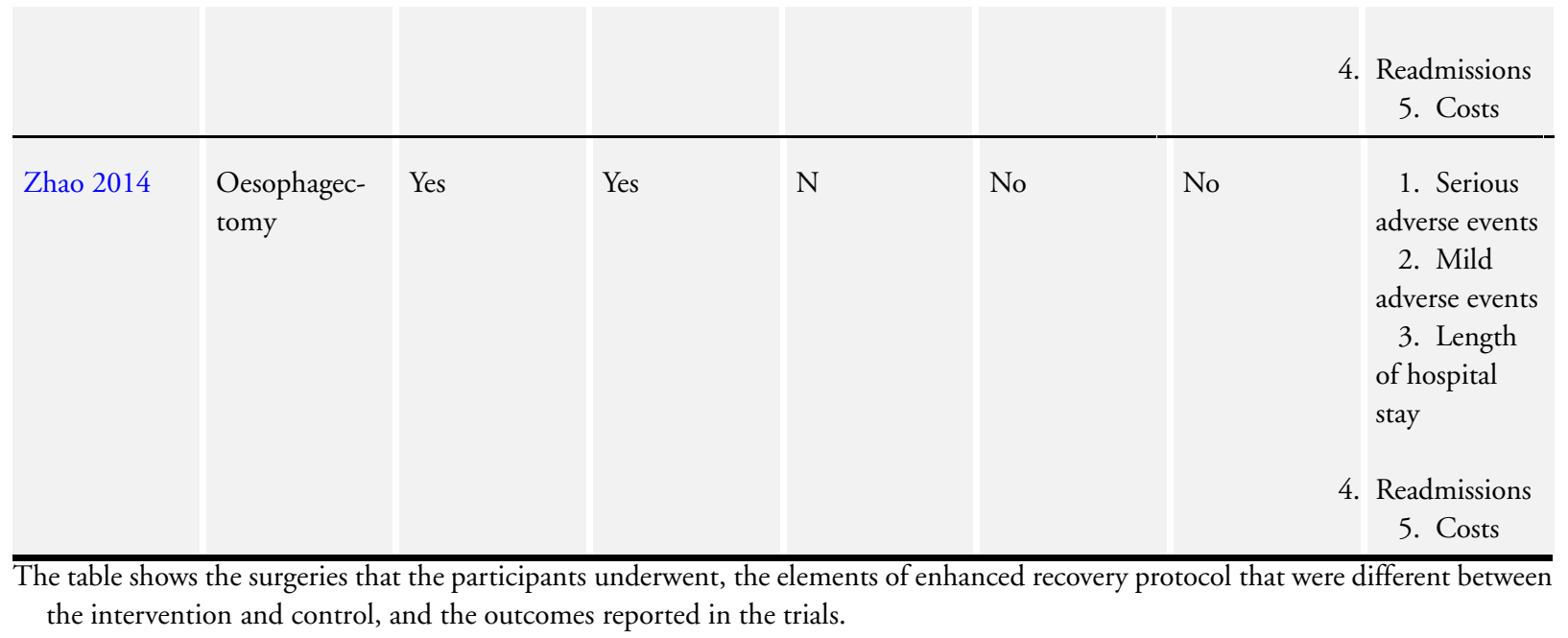

\section{A P P E N D I C E S}

\section{Appendix I. CENTRAL search strategy}

((enhanced near $/ 5$ recovery) or (fast-track near/5 recovery) or (fast-track near/5 rehabilitation) or ERAS)

\section{Appendix 2. MEDLINE search strategy}

1. ((enhanced adj5 recovery) or (fast-track adj5 recovery) or (fast-track adj5 rehabilitation) or ERAS).mp.

2. randomized controlled trial.pt.

3. controlled clinical trial.pt.

4. randomized.ab.

5. placebo.ab.

6. drug therapy.fs.

7. randomly.ab.

8. trial.ab.

9. groups.ab.

10. 2 or 3 or 4 or 5 or 6 or 7 or 8 or 9

11. exp animals/ not humans.sh.

12. 10 not 11

13. 1 and 12 


\section{Appendix 3. EMBASE search strategy}

1. ((enhanced adj5 recovery) or (fast-track adj5 recovery) or (fast-track adj5 rehabilitation) or ERAS).mp.

2. Clinical trial/

3. Randomized controlled trial/

4. Randomization/

5. Single-Blind Method/

6. Double-Blind Method/

7. Cross-Over Studies/

8. Random Allocation/

9. Placebo/

10. Randomi?ed controlled trial\$.tw.

11. Rct.tw.

12. Random allocation.tw.

13. Randomly allocated.tw.

14. Allocated randomly.tw.

15. (allocated adj2 random).tw.

16. Single blind $\$$.tw.

17. Double blind $\$ . t w$.

18. ((treble or triple) adj blind\$).tw.

19. Placebo\$.tw.

20. Prospective study/

21. or $/ 2-20$

22. Case study/

23. Case report.tw.

24. Abstract report/ or letter/

25. or/22-24

26. 21 not 25

27. 1 and 26

\section{Appendix 4. Science Citation Index search strategy}

\# $1 \mathrm{TS}=(($ enhanced near $/ 5$ recovery) or (fast-track near $/ 5$ recovery) or (fast-track near $/ 5$ rehabilitation) or ERAS)

\# 2 TS=(surgery OR surgeries OR surgical OR operation OR operations OR procedure OR procedures)

\# 3 TS=(random* OR rct* OR crossover OR masked OR blind* OR placebo* OR meta-analysis OR systematic review* OR metaanalys*)

\# 4 \#3 AND \#2 AND \#1

\section{Appendix 5. ClinicalTrials.gov search strategy}

Four searches were performed.

1. Interventional Studies | enhanced recovery | Phase 2, 3, 4

2. Interventional Studies | fast-track recovery | Phase 2, 3, 4

3. Interventional Studies | fast-track rehabilitation | Phase 2, 3, 4

4. Interventional Studies | surgery | ERAS | Phase 2, 3, 4 


\section{Appendix 6. WHO ICTRP search strategy}

Enhanced recovery or fast-track recovery or fast-track rehabilitation or ERAS

\section{WHAT'S NEW}

Last assessed as up-to-date: 26 March 2015.

\begin{tabular}{l|l|l}
\hline Date & Event & Description \\
\hline 2 February 2016 & Amended & Amendment to External Souces of Support statement. \\
\hline
\end{tabular}

\section{CONTRIBUTIONSOFAUTHORS}

Conceiving of the review: KG

Designing the review: KG

Co-ordinating the review: $\mathrm{KG}$

Designing search strategies: KG

Data extraction: GB-S, AB, KG

Data analysis: KG

Writing the review: KG, GBS

Providing critical comments on the review: $\mathrm{AB}, \mathrm{BRD}$

Securing funding for the review: KG, BRD

Performing previous work that served as the foundation of the current study: KG

\section{DECLARATIONSOF INTEREST}

This report comprises independent research funded by the National Institute for Health Research (NIHR) Cochrane Programme Grants, 13/89/03 (Evidence-based diagnosis and management of upper digestive, hepato-biliary and pancreatic disorders). The views expressed in this publication are those of the review author(s) and are not necessarily those of the National Health Service (NHS), the NIHR or the Department of Health.

GB-S: none known.

$\mathrm{AB}$ : none known.

BD: none known.

KG: none known. 


\section{SOURCES OF SUPPORT}

\section{Internal sources}

- University College London, UK.

\section{External sources}

- National Institute for Health Research, UK.

This project was supported by the National Institute for Health Research, via Cochrane Programme Grant to the CHBG and UGPD groups. The views and opinions expressed therein are those of the authors and do not necessarily reflect those of the Systematic Reviews Programme, NIHR, NHS or the Department of Health.

\section{DIFFERENCES BETWEEN PROTOCOLANDREVIEW}

Although we did not find multi-arm trials, if we find multi-arm trials in future, we will present the analysis by pooling the intervention groups and comparing it with control as the main analysis. Comparing each intervention with a split control group to avoid double counting will be presented as sensitivity analysis. This is following the recommendation of a statistician.

Different methods of dealing with multi-arm trials were planned as a subgroup analysis; however, this has been moved to the sensitivity analysis section as this was an error in the protocol.

The time period for health-related quality of life was revised from four weeks to three months to include any time until three months. This is because none of the trials reported health-related quality of life beyond four weeks. 